\title{
ANALISES DE REVISTAS
}

\begin{abstract}
Mecan ismos vestihulares facilitadores e inibidores de reflyox medulares (VestiBULAR MECHANisms OF FACILITATION AND INHIBITION OF CORD REFlexes). B. E. Gernandt e C. A. 'Thulix. Am. J. Physiol., 172:653, 1953.
\end{abstract}

E' sabido que o sistema vestibular age positivamente sôbre os centros motoreg periféricos e isso se tornou mais patente após a demonstração da existência de influxos facilitatórios sôbre a medula, vindos dos núcleos vestibulares em resposta à estimulação elétrica (Bach e Magoun). Com o fim de analisarem acurarlamente êsse efeito, os AA. o estudaram em gatos, servindo-se de técnica delicada, que Ihes permitiu registrar o potencial de ação de um reflexo monossináptico do membro posterior provocado elètricamente, tanto $\mathrm{em}$ condições de repouso, como durante a estimulação dos canais semicirculares horizontais.

$O$ que se depreende das experiências efetuadas por Gernandt e Thulin pode resumir-se no seguinte: há um fluxo espontâneo contínuo de estímulos que passa pelos nervos vestibulares, mesmo durante o repouso completo. A secção dos nervos vestibulares provoca acentuada depressão do potencial de ação desenvolvido pelo reflexo monossináptico em estudo, com aumento da latência. A estimulação dos canais semicirculares horizontais (por rotação do animal com velocidade angular bem controlada) provoca sensiveis alterações no potencial de ação registrado durante o reflexo. Assim, a rotação horizontal do animal em direção do lado em experiência, durante a provocação de um reflexo de flexão monossináptico de nivel lombar (via aferente $L_{\tau}$ ), levou a um aumento de 200 a $300 \%$ do potencial registrado; tal aumento era tanto maior quanto maior a velocidade angular. A parada brusca da rotação, provocando um movimento ampulófugo rápido da endolinfa, reflete-se imediatamente como baixa do potencial do reflexo, o que indica a inibição que êsse fenômeno desencadeia sôbre o neurônio periférico. Exatamente o inverso se pode obter com a rotação do animal no sentido contrário, isto é, inibição do reflexo durante a rotação e facilitação após a parada brusca; do mesmo modo, o grau de inibição ou de facilitação varia com a velocidade angular.

Interessante é notar que, quando as mesmas experiências foram repetidas usando-se um reflexo não de flexão mas de extensăo, os resultados foram contrários aos descritos. Disso se conclui que o aparêlho vestibular tem influência decisiva sôbre a inervação recíproca, fato êsse mais do que provado, porquanto a secção do nervo vestibular ipsilateral (em relação ao reflexo) faz desaparecer tal reciprocidade, de modo que as respostas são sempre iguais, quer para os reflexos extensores, quer para os flexores.

Quais as vias implicadas nesses mecanismos? Sabemos que a ação vestibular sôbre a medula se faz através dos tractos vestibulospinal e reticulospinal. A secção do tracto vestibulospinal não modificou apreciàvelmente a resposta dos reflexos estudados (a seç̧ão do tracto reticulospinal não foi feita por causa da situação dêsse tracto, encravado na parede do sulco mediano anterior). Conclui-se que é principalmente através das vias reticulospinais que o aparêlho vestibular provoca os reflexos compensadores do equilíbrio que lhe estão afetos (pelo menos no gato, animal que dispõe de um sistema reticular altamente desenvolvido). $\mathbf{E}$, mais, que as respostas vestibulares "estão organizadas para ação recíproca sôbre os extensores e flexores, mesmo quando iniciadas no nível reticular".

A descoberta, assim feita, da possibilidade de respostas seletivas a partir da formação reticular, contraria a opinião corrente de que a atividade reticular é sempre indiscriminada, difusa, e abre perspectivas novas no sentido de se investigar a ação mesma dêsse setor do SNC por meios indiretos precisos que contornem 
a possibilidade de erros, determinados pela difusão das correntes quando se faz sua estimulação direta.

Cesar Timo Iaria

O Sistema extrapiramidal: considerações a respeito da veracidade de seu conceito ('THE EXTRAkYRAMIDAI, SYSTEM: AN INQUIRY INTO THE VALIDiTY OF THE CONCEPT). R. Meyers. Neurology, 3:627-655 (setembro) 1953.

Estudando o sistema extrapiramidal sob o ponto de vista embriológico, anatômico, fisiológico e clínico-patológico, e comparando-o ao sistema piramidal, o $\mathbf{A}$. discute a veracidade do conceito dêsses dois sistemas, salicntando que inesmo nas experimentações mais recentes e que têm sido a origem de novas teorias sôbre a constituição de ambos os sistemas, os resultados não podem ser atribuídos ùnicamente a um dêles. Assim é que, comentando as conclusões obtidas por vários autores após seç̧ões do tracto piramidal ao nível dos pedúnculos e da medula alongada, o A. lembra que os movimentos voluntários são gravemente diminuídos, mas não são abolidos definitivamente; que a movimentação voluntária, considerada por muitos como privativa do sistema piramidal, pode ser abolida também em virtude de lesões em muitas outras partes do sistema nervoso, tais como o corpo restiforme, a decussação do brachium conjunctivum, as fibras do campo $\mathrm{H}_{1}$ de Forel, núcleo ventrolateral do tálamo, etc.. Quanto à "praxis", também considerada como tunção piramidal, pode ser alterada por lesões de fibras consideradas extrapiramidais. Critica o A. o trabalho de vários experimentadores que conclue.n romo sendo piramidais as lesões resultantes da ablação de áreas corticais, esquecendo-se que muitas das fibras ali originadas vão terminar ao nível de estruturas reconhecidamente de função extrapiramidal, como sejam o núcleo rubro, substância negra, corpo subtalâmico, etc.. Listudando as lesões encontradas por vários autores em casos de enfermos com quadros clínicos de moléstia extrapiramidal, Meyers chama a atenção para o fato de que lesões circunscritas a uma estrutura anatômica particular, como sejam o globo pálido, o putâmen e o núcleo caudado, tenham sido responsabilizadas por vários tipos de hipercinesias, como sejam a distonia, atetose, coréia, torcicolo espasmódico, balismo, tremor alternante, etc.. Do mesmo modo, os autores não são concordes quanto à localização das lesões em um mesmo quadro clínico, como seja o parkinsonismo, por exemplo. O A. crê que se deva considerar ambos os sistemas - piramidal e extrapiramidal - apenas como sistemas motores, desde que nào se pode considerar como sendo extrapiramidais todos aquêles mecanismos aferentes relacionados à função motora e que não pertençam ao sistema piramidal. Aconselha o A. que o problema seja estudado sob os pontos de vista anatômico, funcional e patológico, procurando-se sistematizar a nomenclatura usada para descrever as alterações motoras e a catalogação das lesões cerebrais encontradas nas diferentes sindromes clínicas. $O$ presente trabalho merece ser lido por todos aquêles que se interessam pelos problemas neurológicos, pois evidencia muito bem as dificuldades que se nos deparam freqüentemente no estudo ciêsses dois sistemas

J. Armbrust-Figueiredo

Paraplegia em flexão de origem cerebral (Paraplegia in plexion of cerebral origin). P. I. Yakovlev. J. Neuropathol. a. Exper. Neurol., 13:267-296 (janeiro) 1954.

Yakovlev, continuando uma série de estudos que vem realizando sôbre a organização dos atos motores e sua integração em variados níveis do sistema nervoso central, visa, neste trabalho, expor os característicos clínicos cardinais da paraplegia 
em flexão de origem cerebral e as lesões com as quais esta síndrome está comumente associada. Excetuando raros casos em que a paraplegia em flexão se instala de modo brusco, no geral a síndrome se instala progressivamente em pacientes nos quais a anamnese revela a existência de uma afeç̧ão cerebral crònica difusa (encefalopatias congênitas ou adquiridas na primeira infância, seja traumáticas ou de outra natureza, escleroses difusas, moléstias de Pick ou de Alzheimer, neurolues, arieriosclerose cerebral); às vêzes, ela se instala em pacientes portadores de lesões inicialmente localizadas e mesmo unilaterais (hemiplegias), sendo de interêsse verificar que, em tais circunstâncias, a contratura em flexão se instala mais precocemente e é mais intensa no membro inferior contralateral à hemiplegia primitiva.

A evolução se dá em três fases. A primeira caracterizada por contrações oposicionistas aos movimentos passivos (Gegenhalten de Kleist, rigidez paratônica de Dupré) e na qual o esfôrço do paciente em cooperar tende a aumentar sua impossibilidade para inibir a perseveração involuntária da inervação tônica durante a movimentação passiva; já nesta fase aparecem sinais de decadência mental e apatia emocional aos estímulos exteriores, embora não existam distúrbios sensitivos elen.entares. $\mathrm{Na}$ segunda fase - atitude de flexão - a rigidez muscular se torna nitidamente axial e pelvi-crural quanto à distribuição; trata-se, agora, de rigidez de postura, muito semelhante à que se observa nos quadros de parkinsonismo, preaominando a hipertonia dos flexores tanto nas atitudes como nos movimentos (atitude em flexão, tanto na posição erecta como no decúbito, com rigidez de tipo plástico, exagêro dos reflexos axiais, distúrbios da palavra e, eventualmente, reaparecimento dos reflexos de sucção e de preensão forçada, astasia-abasia). Na terceira fase - contratura pelvi-crural em flexão - os pacientes permanecem acamados com os membros inferiores fletidos sôbre o abdome, sendo a contratura mais nítida nos flexores e adutores das côxas e nos flexores das pernas; progressivamente a flexão vai-se acentuando e, nos estádios finais, atingidos os membros superiores, o corpo do paciente assume a atitude fetal, demonstrando a liberação progressiva dos mecanismos motores hieràrquicamente inferiores, que tinham sido inibidos durante o desenvolvimento ontogenético.

Yakovlev apresenta documentação anátomo-patológica de 11 cérebros e 5 medulas obtidos de pacientes cuja doença evoluiu até o seu último têrmo, com profunda demência e extrema paraplegia em flexão. Nenhuma das medulas exibiu lesões que explicassem o quadro paraplégico. Nos cérebros, de maneira geral fora:n notadas degenerações globais na corticalidade, predominando nìtidamente nas regiões frontais anteriores, onde o processo de gliose substitutiva era intenso; nos núcleos da base as lesões, embora difusas, eram mais nítidas nas partes externas do globo pálido. Em todos os casos as lesões diminuíram de intensidade da parte anterior para a posterior do cérebro. $\mathrm{Em}$ todos foi notada a preservação da estrutura cito e mieloarquitetônica do córtex cerebelar. No tronco cerebral a degeneração nítida dos feixes descendentes do sistema extrapiramidal contrastava com a relativa conservação dos grandes sistemas descendentes piramidais e ascendentes sensitivos; íntegros estavam os sistemas cerebelostriados do pedúnculo cerebelar superior. Estas lesões explicam dois fatos verificados nas paraplegias em flexão de origem cerebral e que as diferenciam dos paraplégicos em flexão de origem medular: a relativa conservação da motricidade voluntária e a integridade da sensibilidade.

$D_{a}$ correlação anátomo-clínica dos fatos que observou, Yakovlev tira deduçõas importantes para explicar o mecanismo fisiológico dos paraplégicos em flexão de origem cerebral. As degenerações corticais difusas, especialmente frontais, explicariam a apatia, a perda de iniciativa motora, a perda das reações de contacto com o meio ambiente, extrapessoal; por outro lado, a conservação da sensibilidade, especialmente da proprioceptiva e a liberação dos mecanismos tonígenos diencéfalomesencefálicos produziria o exagêro dos reflexos dependentes de excitação proprioceptiva e cutânea. Aplica Yakovlev, aqui, as idéias de Babinski e Jargowski sôbre a hiperpatia pseudo-afetiva aos estímulos cutâneos condicionando um estado per- 
manente de contratura pelvi-crural em filexão, ao qual podem-se associar reações bruscas de tríplice flexão (reflexos de defesa), quando seja feita uma excitação cutânea ou proprioceptiva de maior intensidade. No entanto, do ponto de vista clínico, cabe diferençar as reações de tríplice flexão - mero automatismo medular - da contratura permanente de origem cerebral, pois as primeiras são inicialmente caudipodais e ulteriormente pelvi-crurass, ao passo que a segunda se inicia pela contratura de músculos da côxa e da bacia (pelvi-crural).

Assim, a documentação anátomo-clínica apresentada sugere que, para o aparecimento da reação de flexão pseudo-afetiva hiperpática e de contratura pelvi-crural em flexão é necessária a combinação de lesões degenerativas intensas nos lobos frontais e de lesões nas partes externas do globo pálido; a paraplegia em flexão é facilitada quando esta combinação de lesões se desenvolve em um cérebro que apresente alterações difusas, embora de menor monta (encefalopatias congênitas ou adquiridas na primeira infância ou lesões degenerativas de origem vascular). A relativa conservação do córtex das regiões centrais e dos feixes piramidais parece favorecer a instalação da paraplegia em flexão, mas a integridade das vias sensitivas tálamo-aferentes é essencial para a produção da síndrome.

O. LANGE

Mrcanisuos do coma (Coma mechanisms). J. F. Fazeras e A. N. Bessman. Am. J. Med., 15:804-812 (dezembro) 1953.

Muitas desordens cerebrais resultam de distúrbios metabólicos do sistema nervoso central, em graus paralelos e dependendo também da importância funcional da região cerebral afetada. Qualquer que seja a causa, se houver falta de energia metabólica, de intensidade e duração suficiente, surgirão distúrbios funcionais que poderão conduzir ao coma e ao dano celular irreversível. Ao lado da chegada do material necessário para o metabolismo, são indispensáveis enzimas para catalisar êsse material, permitindo as reações entre o substrato e o exigênio. Portanto, qualquer distúrbio que interfira com a chegada do substrato, com a atividade dos enzimas ou o suprimento de oxigênio às células cerebrais, deve necessàriamente alterar a função nervosa. De acôrdo com êsses princípios, os AA. distinguem quatro grupos fundamentais de mecanismos de alterações da função cerebral: por insuficiência do substrato, por distúrbios enzimáticos, por insuficiência dè oxigênio e por diversas outras etiologias.

No primeiro grupo, incluem-se os comas dependentes de uma chegada insuficiente de glicose (comas pós-hipoglicêmicos). Realmente, as células cerebrais obtêm sua energia primàriamente da oxidação da glicose; essas células são também capazes de oxidar certos aminoácidos, assim como alguns ácidos gordurosos são tamb́́m sintetizados dentro do cérebro. Entretanto, como êstes dois últimos elementos são insuficientes para manter o funcionamento cerebral, compreende-s: como a falta de glicose no meio circulante conduza ao coma. De fato, nos comas hipoglicêmicos há um fluxo sangüíneo cerebral normal, um suprimento também normal de oxigênio, mas êste é consumido em quantidade reduzida pelo tecido cerebral. O teor do consumo cerebral de oxigênio no coma hipoglicêmico se normaliza quando soluções glicosadas são administradas, donde a conclusão de que não estava em jộo qualquer distúrbio enzimático. Após um lapso de tempo prolongado, o dano celular cerebral se torna irreversível, de forma que mesmo injeções de glicose não normalizam mais o baixo teor do consumo cerebral de oxigênio. A rhegada de uma quantidade global baixa de oxigênio no cérebro pode depender do uma redução do fluxo sangüíneo cerebral, o que explica a suscetibilidade individual variável à hipoglicemia, assim como o fato de que diabéticos idosos, com arteriosclerose, apresentam por vêzes distúrbios hipoglicêmicos em níveis de glicemia mais ou menos normais. Outra possibilidade é a existência de alterações da difusibilidade da glicose dos vasos para as células nervosas. 
No segundo grupo, há ainda algumas dúvidas derivadas das discussões sôbre - modo preciso da oxidação da glicose pelas células cerebrais, antes de chegar à produção de energia sob a forma de compostos fosfatados. Essas diversas reações são realizadas pela interferência de enzimas e coenzimas. Qualquer distúrbio na atividade destas últimas pode comprometer a utilização da glicose e levar ao sof rimento cerebral, eventualmente ao coma. Esses distúrbios poden depender da falta de enzimas ou de coenzimas, estas últimas em geral componentes do complexo vitamínico B. A deficiência tiamínica é representada, esquemàticamente, pela síndrome de Wernicke, na qual o metabolismo cerebral se encontra diminuído e se normaliza após a administração da vitamina $B_{1}$. Outros sintomas neurológicos podem surgir pela deficiência da nicotinamida (distúrbios mentais da pelagra) e experimentalmente no déficit do ácido pantotênico. Ao que parece, a vitamina $B_{12}$ age como coenzima na oxidação específica em uma síntese intermediária essencial, de modo a explicar o aparecimento de lesões nervosas independentemente do quadro hematológico, nas síndromes neuranêmicas. Além da falta de enzimas, por carências de qualquer tipo, a atividade enzimática pode estar simplesmente inibida, como acontece em intoxicações por metais pesados (chumbo e arsênico). Esses metais, ao que parece, anulam as coenzimas, permitindo o aparecimento de um quadro semelhante ao da avitaminose $B_{1}$. A ação inibitória se processa sôbre o radical tiol; assim se compreende a ação benéfica do BAL (composto tiol), o qual objetivamente aumenta o consumo cerebral de oxigênio, prèviamente reduzido pelo processo tóxico. O coma diabético representa bem, igualmente, o tipo de distúrbio neurológico por inibição de atividade enzimática. De fato, a insulina supera a ação inibidora da hipófise anterior e do córtex suprarrenal sôbre a enzima hexoquinase e facilita as reações de outros intermediários. No coma diabético há redução do consumo cerebral de oxigênio, mas o fluxo sangüíneo cerebral, a resistência cérebro-vascular e o suprimento de oxigênio são constantes, de modo que se acha em jôgo uma inibição (de mecanismo ainda mal conhecido) da atividade enzimática cerebral. No coma urêmico parece haver, também, umia inibição hematogênica de enzimas cerebrais, enquanto que, no coma hepático, sugeriu-se haver uma incapacidade do cérebro remover o íon amônia circulante, com conseqüente intoxicação. $O$ álcool e os barbitúricos podem inibir a oxidação da glicose cerebral; outras vêzes, ao que se pensa, existe uma dissociação no processo de formação dos compostos fosfatados de alta energia pela oxiḍação, embora a mesma se processe normalmente ("uncoupling"). Além de carentes ou inibidas, as enzimas podem ser destruídas, como acontece em certas infecções a vírus ou talvez em algumas doenças degenerativas.

No terceiro grupo são considerados os casos de suprimento insuficiente de oxigênio ao cérebro, de modo a não permitir uma oxidação conveniente da glicose: asfixia, parada cardíaca, arteriosclerose, anemias graves, etc..

Finalmente, no quarto grupo, os AA. citam casos de diversas etiologias, como os comas traumáticos e tumores cerebrais, em que provàvelmente diversos fatôres estão concomitântemente em causa.

R. Mei.aragno Filho

Estudos sôbre a pressão da artéria canótiba em pacientes submetidos a angio-

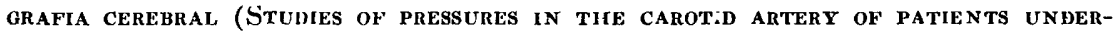
going cerebral angiograpity), W. F. Stern. J. Neurosurg., 10:577-582 (novembro) 1953.

O sucesso terapêutico da ligadura de uma grande artéria cerebral no tratamento de malformações vasculares cerebrais depende, de um lado, da queda de pressão ao nível do processo patológico e, de outro, do não aparecimento de sintomas neurológicos pós-operatórios. 'Trabalhos anteriores haviam registrado a pressão da carótida interna antes e depois da oclusão da artéria carótida ipsilateral 
e bilateral simultânea; os resultados obtidos sugeriam a utilidade da determinação das pressões carotídeas durante a oclusão bilateral para avaliar a permeabilidade ou não dos principais ramos comunicantes do círculo de Willis.

Neste trabalho, stern estudou a pressão arterial intracarotídea, por determinação direta, durante a oclusão da artéria ipsilateral e bilateral. Os resultados foram cotejados com a de.nonstração angiogrurica do enchimento das porções anteriores e posteriores do círculo de Willis e do enchimento bilateral após injeções unilaterais. Com o método empregado, não se evidenciou correlação nítida entre o grau de queda de pressão após a oclusão arterial ipsilateral e bilateral, e a presença ou ausência de enchimento bilateral da metade anterior do círculo de Willis ou o enchimento da metade posterior ipsilateral. O A. acredita que o enprêgo isolado da angiografia não fornece informações suficientes para se predizer se são ou não eficazes, em determinado caso, os mecanismos de distribuição do círculo de Willis.

R. Melaragio Fitho

Complicações da anglografia cerebral (Compilications following cerebrat angiography). D. M. Perese, W. C. Kite, A. J. Bedell e E. Campreit.. Arch. Neurol. a. Psychiat., 71:105-115 (janeiro) 1954.

$\Lambda$ pesar do indiscutivel valor da angiografia cerebral, deve-se reconhecer que êsse processo semiológico não é isento de riscos. Estes últimos são estudados no presente trabalho, em que se apontam algumas contra-indicações. Os AA. estudaram vasto material constituído por 234 arteriografias consecutivas da carótida, executadas em 200 pacientes, entre 194.7 e 1952, e nas quais empregarm sempre o Diodrast a $35 \%$. O método aberto de exposição da carótida foi empregado em 33 casos e o percutâneo nos 201 restantes. No conjunto, registraram-se 37 complicações. Destas, uma foi mortal e atribuída indubitàvelmente ao uso de quantidades excessivas do contraste. Em 6 casos, em que o estado geral dos pacientes já era extraordinàriamente precário, a angiografia aparentemente apressou a morte. Dêsses 6 casos, 4 apresentavam amplas tromboses arterioscleróticas, outro morreu por rotura de aneurisma da vertebral e o último, por metástases múltiplas de carcinoma brônquico. 'Irês casos de hemiplegia permanente e 19 de transitória foram observados; a complicação neurológica deve ser atribuída ao processo semiológico em consideração. Alterações sensitivas contralaterais e transitórias ocorreram em 6 pacientes. Finalmente, em um paciente, fotografias seriadas demonstraram uma oclusão parcial da artéria retiniana.

Os AA. concluem que o método não é isento de riscos, de forma que, se outro exame pode, em dado caso, suprir a angiografia, esta última não é justificável. Por outro lado, acreditam que se faz mister a descoberta urgente de uma substância mais segura que o Diodrast.

R. Melaragno Firho

Configuração angtográfica dos tumores metastáticos intracerebrais (The angiographic configuration of intracerebral metastatic tumors). S. Ethelberg e K. Vaernet. Radiology, 61:39-48 (julho) 1953.

Lembram os AA. que os problemas da localização e identificação dos tumores cerebrais pela angiografia estão pràticamente resolvidos com relação aos meningeomas e aos gliomas malignos, o mesmo não sucedendo quanto aos tumores metastáticos do cérebro, justamente o grupo de tumores em que há grande interêsse na identificação pré-operatória, a fim de que seja escolhida uma orientação terapêutica adequada. Wickbom descreveu un determinado arranjo angiográfico em 
12 casos de tumores metastáticos, dos 24 por êle estudados. De um mode geral, porím, não ficaram estabelecidos quadros angiográficos típicos dêstes tumores.

(O) AA. estudaram 39 casos de tumores metastáticos supratentoriais, localizados nos hemisférios cerebrais. Dos 39 casos, a angiografia foi praticada em 21, sendo obtidos angiogramas úteis em 21, que são os casos apresentados. Os tuinores primitivos dêstes casos tinham as seguintes localizações: câncer brônquico (3); hipernef roma (4); câncer da suprarrenal (1); adenocarcinoma do tracto digestivo (2); adenocarcinoma da mama (2) e seminoma (1). Em 2 casos a verificação foi operatória e nos outros foi de necrópsia. As metćsiases múltiplas foram em número de 5. Ém 12 casos a localização era pariatoccipital e, em 4, central e précentral. Depois de estudar detalhadamente os aspectos angiográficos dêstes tumores, comparando-os com os dos meningeomas e dos gliomas e dêles diferençando-os, os AA. descrevem os seguintes elementos angiográficos, que consideram característicos dos tumores metastáticos cerebrais: 1) se a circulação endoneoplástica puder ser demonstrada, ela se apresenta ou como mancha opacificada, mais ou menos circular, com cêrca de 15 a $25 \mathrm{~mm}$ de diâmetro, onde não se distinguem vasos com nitidez, ou como um feixe de artérias delicadas, de trajeto circular ou semicircular. circundado por uma área avascular; 2) a área de vascularização anormal quase sempre se localiza nos territórios terminais de determinada artéria, o que ocorre com as localizações corticais ou subcorticais do tumor; 3) uma ou mais delicadas artérias de suplência, ramos da cerebral anterior ou da cerebral média, foram observadas em 15 dos 21 casos; 4) embora o tumor se possa localizar em qualquer área cerebral, a localização predileta é nos territórios cerebrais, onde se encontram os ramos terminais mais calibrosos da carótida interna, isto é, parietal posterior e artéria do gyrus angularis; 5) o descolamento das artérias adjacentes é pequeno e muito localizado, quando ocorre; 6) não há modificaçôes evidentes na configuração vascular extracerebral; 7 ) a multiplicidade de lesões é raramente vista nos angiogramas e, se ela ocorre, indica metástase intracerebral.

\section{Pereina da Silva}

Patogenia das paralisias de nervos cranianos associadas a aneurismas intracraNiANCS ('l'he Pathogenes:s OF cranial NeRves palsies associated with intiacranial anecrysms). H. H. Hyiand e H. J. M. Barnett. Proc. Roy. Soc, Med. (Section of Neurology), 4\%:141-146 (fevcreiro) 1954.

Revisão de 94 casos anátomo-clínicos de aneurismas intracranianos, sendo 39 com paralisias de nerves cranianos, entre os quais predominou nitidamente o oculomotor. Lim 20 casos o aneurisma entrava em contacto direto com 0 nerve $\epsilon$ nascia mais freqüentemente da porção anterior do círculo de Willis. Em 15 dêsses casos havia sinais de extravasão de sangue. O comprometimento funcional do nervo coincide, em geral, com herorragias dos aneurismas. Os próprics nervos, entretanto, quase sempre apresentavam hemorragias, reccntes ou antigas. A compressão do nervo por um aneurisma pulsátil pode não causar sintomas em vista da grande capacidade de adaptação; porém, uma brusca dilatação, mesmo sem hemorragia, pode distender o nervo ou causar edema e hemorragia devidos a obstrução venosa.

Em 19 casos a paralisia, geralmente bilateral, foi devida a mecanismos secundários conseqüentes a hemorragia intracraniana: a) hemorragias mesencefálicas causadas por comprcssão direta do pedúnculo pcla hemorragia de um ancurisma situado posteriormente; b) angulação e compressão do nervo oculomotor contralateral, pelo deslocamento da cerebral posterior; c) compressão por hérnia do uncus; d) distensão ou co.mpressão do tronco encefálico devido a súbita hemorragia intracerebral e intraventricular.

H. Canelas 
Moléstia de Schilder-Foix. Estudo anátomo-clínico de om caso (Maladie de Schilder-Folx. Etude anatomo-clinique d'Un cas). J. de Ajuriaguerra, H. Hecaen e J. Fretet. Presse Méd., 61:1756-1759 (25 dezembro) 1953.

O quadro da moléstia de Schilder-Foix pode ser reconhecido, em pacientes jovens, por uma tríade sintomática: deterioração mental, quadriplegia espástica e distúrbios visuais; a essas perturbações, podem acrescer uma síndrome afaso-agnóstico-apráxica, crises convulsivas, sintomas cerebelares e sensoriais. A evolição se proccssa para a caquexia e morte, a qual ocorre, em geral, de alguns meses a um ano. Anatômicamente, trata-se, na maior parte das vêzes, de desmielinização simétrica, afetando a substância branca e poupando a cinzenta, assim como os cilindros-eixos. Histològicamente, caracteriza-se por lesões do tipo da encefalite com reações inflamatórias mais ou menos intensas. No presente trabalho, os AA. apresentam o caso de um menino de 8 anos, em que certos aspectos clínicos e anátomopatológicos se afastavam do quadro clássico da afecção; a evolução desde o início da doença até a morte se processou em 22 meses; a doença principioa por distúrbios do humor e do caráter, além de perturbações visuais; logo após inércia psicomotora, com redução da liøguagem e decadência intelectual, estado que se agravou ràpidamente; as perturbações visuais evoluíram para a cegueira cortical; os sinais piramidais se pronunciaram e surgiram distúrbios do equilíbrio e vestibulares; a linguagem se alterou quer no sentido da expressão quer no da compreensão; pouco a pouco, instalou-se quadriplegia em flexão; apenas tardiamente, o estado geral manifestou comprometimento grave; o EEG muito precocemente evidenciou desorganização da atividade elétrica cerebral. O estudo anátomo-palológico denonstrou uma desmielinização centro-lobar, com conservação das fibras em $U$, predominando nos lobos temporais e occipitais. As particularidades anatômicas desta observação consistem na extensão das lesões para a região pontina, comprometimento dos núcleos cinzentos centrais, especialmente do bordo capsular do núcleo lenticular e das partes externas do tálamo, com desmielinização e infiltrados perivasculares no quiasma e nervos ópticos.

R. Melaragno Filho

'Tumores da medula espinhal em crianças: revisão do assunto e apresentação de 20 casos (Spinal cord tumors in Childeen: a Review of the subJect and presentation of twenty cases). F. M. Anderson e M. J. Carson. J. Pediat., 43:190-207 (agôsto) 1953.

Os AA. fizeram a revisão de 21 casos de tumores intra-raqueanos observados em crianças de 5 meses a 14 anos de idade, estudadas em um período de 22 anos. Us AA. só incluíram no presente trabalho os casos cujos sintomas decorriam exclusivamente de neoplasmas intra-raqueanos.

$\mathrm{Na}$ revisão da literatura sôbre o assunto, mencionam o trabalho de Hamby, que estudou 214 casos de crianças menores de 15 anos de idade, que apresentavam tumores intra-raqueanos, tendo verificado que os gliomas e os sarcomas extradurais eram cs tuniores mais frequientes nestas idades, seguindo-se os tumores congênitos, os neurofibromas e os meningeomas. Verificou Hamby que o meningeoma era raramente encontrado em crianças menores de 12 anos. O sarcoma foi verificado em tôdas as idades, enquanto que o glioma era observado raramente antes dos 4 anos de idade. Relativamente à frequência dos tumores intra-raqueanos e cerebrais na criança, citam os dados de Bailey, que encontrou um caso de tumor intra-raqueano para 20 casos de tumores cerebrais na criança, enquanto que, no adulto, a proporção verificada por Bailey foi de um tumor intra-raqueario para 6 tumores cerebrais. No hospital em que trabalham os AA. a proporção foi de um tumor intra-raqueano para 8 tumores cerebrais, em crianças menores de 14 anos. 
Com relação aos aspectos clínicos dos tumores intra-raqueanos em crianças, observaram os AA. que os sintomas determinados por êstes tumores diferiam consideràvelmente daqueles observados em adultos, o que atribuíram principalmente à incapacidade das crianças em descreverem certos sintomas, tais como adormecimentos e fraqueza dos membros, assim corno distúrbios esfinctéricos. Outro fato refere-se à falta de sintomas objetivos de tumor intra-raqueano, o que observaram em 4 casos, onde a sintomatologia era constituída apenas de dôres lombares e radiculares e espasmos dos músculos lombares e da articulação do joelho. Acentuam que, em tais casos, muitas vêzes é feito o diagnóstico de histeria, desvios congênitos da coluna, espondilite tuberculosa, hérnia do núcleo pulposo, etc., sendo instituídas terapêuticas tais como correção ortopédica, psicanálise e outras. Inversamente, podem os tumores intra-raqueanos benignos ou malignos se apresentar abruptamente com uma sintomatologia neurológica exuberante, podendo mesmo trazer confusão com a mielite transversa, a síndrome da Guillain-Barré ou o abssesso epidural. Uutras vêzes ainda, o tumor intra-raqueano determina quadros neurológicos sugestivos de poliomielite anterior aguda, com febre, rigidez de nuca e pleocitose no líquor.

Us sintomas mais comumente observados pelos AA. (13 casos) foram dôres de tipo radicular nas costas e nas pernas, com ou sem rigidez e limitação dos movimentos da região cervical e da região lombar. A duração dos sintomas variou neztes pacientes entre 5 semanas e 2 anos. A fraqueza dos membros e os distúrbios da sensibilidade apareceram lentamente em 4 pacientes, e durante êste periodo não foram verificadas modificações evidentes dos reflexos. $\mathrm{Em} 4$ casos o diagnóstico de tumor intra-raqueano foi feito pelo exame do líquiido cefalorraqueano e pela mielografia, pois que o exame neurológico permitiu tal diagnósíico. Em 4 crianças de menos de 2 anos de idade o início da doença se manifestou por irritabilidade, mau humor e fraqueza nos membros inferiores, acompanhada de febre. Em três outras crianças havia diminuição progressiva da sensibilidade e da fôrça nos membros inferiores datando de 2 a 6 meses, sem dôres apreciáveis, e o exame neurológico permitiu o diagnóstico correto da lesão. Distúrbios das funções digestivas e urinárias foram observados em vários graus em 12 pacientes, estavaun ausentes em 5 e não foram mencionados em 4 casos.

Quanto ao exame do líquiido cefalorraqueano, lembram os AA. que alguns dados dêste exame não podem ser aproveitados quando se trata de crianças, tais como a pressão liquórica e a prova de Stookey, por falta de cooperação dêsjes pacientes. Acentuam que o líquor pode-se apresentar ocasionalmente normal, mesmo em se tratando de bloqueio total do canal raqueano; 19 casos dos AA. tininam exame de líquor e em todos havia alterações, sendo a taxa de proteínas elevada em 17 casos, a xantocromia presente em 9. A prova de Queckenstedt evidenciou bloqueio total ou parcial em 8 casos, tendo sido duvidosa em 9 e normal em 2. Em um caso de bloqueio total na mielografia e com taxa de proteína de $3.710 \mathrm{mg} / 100 \mathrm{ml}$, a prova de Queckenstedt foi inteiramente normal. Tratava-se de um caso de neurinoma intradural na altura de $\mathrm{L}_{2}$.

$O$ exame radiológico mostrou modificações patológicas no nível exato da lesão em 14 casos, consistindo estas modificações em erosão dos corpos vertebrais ou das vértebras e dos pedículos em 9 casos, hemangioma do corpo vertebral em 2 casos, escoliose dorsolombar em um caso, fratura por compressão por sarcoma em um caso e perda da lordose cervical em um caso. Recomendam os AA. o exame radiológico cuidadoso de tôda a coluna vertebral nos casos em que a localização clínica não seja exata. Quanto à miclografia, acham-na indispensável, tôdas as vêzes que o exame neurológico não permitir determinar o nível correto da lesão. Ressaltam que o mielograma normal não exclui totalmente a possibilidnde de se tratar de tumor intra-raqueano. A mielografia foi feita em 9 casos dos AA., tendo evidenciado bloqueio completo $\mathrm{\epsilon m} 8$ casos.

Us AA. tratam, a seguir, do diagnóstico dos tumores intra-raqueanos. Quanto ao tratamento, os AA. recomendam a laminectomia exploradora. Lembram que o 
fato da progressão dos sintomas ser, por vêzes, fulminante, não significa que a operação seja inútil, pois com frequiência tumores benignos apresentam evolução rápida. A operação foi praticada em 19 dos 21 casos dos AA., operação que variava desde a biópsia até a remoção total do tumor. Dos casos operados, 3 faleceram um mês ou menos após a operação; tratava-se de casos de hemângio-endotelioma, glioma maligno e extenso ependimoma raqueano e cerebral; dois pacientes melhoraram após a operação, mas houve recidiva dos sintomas em poucos meses (sarcoma extradural e ependimoma dorsal).

Finalizam os AA. lembrando que, embora a percentagem de casos cirùrgicamente favoráveis de tumores intra-raqueanos em crianças ainda seja pequena, é necessário que se esteja atento sempre, a fim de fazer o diagnóstico da condição com tempo suficiente para uma intervenção útil antes que lesões irreversíveis se instalem.

\section{Peneira da Sitva}

Hemichânia hemiplégica familial (Familial hemiplegic migraine). C. W. M. Whitтну. J Neurol. Neurosurg. a. Psychiat., 16:172, 1953.

As manifestações clínicas da enxaqueca são explicadas por uma vasoconstricção inicial no território da carótida interna, seguida de uma vasodilatação nesse território e no da carótida externa. A vasoconstricção seria responsável pela "aura", e a vasodilatação pela cefaléia. Argumentos favoráveis à existência desta vasodilatação seriam a ação da pressão sôbre a carótida ou seus ramos, ou das drogas vasodilatadoras, aumentando a ceỉaléia; èste argumento é corroborado pela ação benéfica dos medicamentos vasoconstrictores sôbre êsse sintoma. $\Lambda$ vasoconstricção inicial, pelo contrário, não é tão fàcilmente aceita. A seu favor estão as observações de que os vasoconstrictores aumentam a duração da "aura", a de que existe nesse momento nítida vasoconstricção nos vasos da retina e as alterações eletrencefalográficas evidenciando sof rimento cerebral localizado, o qual seria devido à isquemia. A observação de casos de crises de enxaqueca seguidas de he riplegia mais ou menos duradoura seria argumento favorável a essa hipótese fisiopatológica.

Após cuidadosa revisão bibliográfica sôbre o assunto e analisando os argumentos favoráveis e os desfavoráveis a essa hipótese, o A. termina por aceitar a teoria do edema cerebral localizado, angioneurótico, de Foster Kennedy, para explicar as hemiplegias e outros distúrbios neurológicos mais ou menos duradouros, pois, a simples isquemia não poderia ser admitida sem um enfarte subseqüente. $\Lambda$ inexistência dêste é provada já pela carência de seqiielas, já pelo desaparecimento dos sinais eletrencefalográficos.

Entretanto, se a fisiopatologia da crise de enxaqueca pode ser assim explicada, nada nos fala a respeito da etiologia. A observação de casos semelhantes com caráter familial, assinı como da existência de disritmias de tipo familiar no EEG, assim como da existência nessas famílias de distúrbios outros como "lapsos de consciência" de tipo comicial, talam por uma gênese dêsse tipo para a enxaqueca. No presente trabalho o $\mathrm{A}$. traz a observação minuciosa de 4 pacientes de enxaquecas seguidas de hemiplegia, com caráter familial e com distúrbios eletrencefalográficos de tipo "disritmia paroxística", bilateral e síncrona, 3 a $6 \mathrm{c} / \mathrm{s}$, muito sensivel à hiperpnéia, cujos familiares apresentavam também crises de "perda de consciência". Já o quinto paciente de sua casuística apresentava crises de enxaqueca seguidas de hemiplegia, não familial, acreditando o $\mathrm{A}$. tratar-se de fenômeno alérgico. 
INTOXicaç̃o pelo chumbo: radiografia do tórax como auxítio ao imagnóstico, (Lead poisoning: roentgenograms of the chest as an aid in diagosis). G. P. Keefer e J. F. Mokrohisky. J. Pediat,, 42:146-151 (agôsto) 1953.

Os AA. lembram que foi Park quem, pela primeira vez, em 1930, chamou a. atenção para as densas faixas observadas nas extremidades dos ossos longos em casos de envenenamento pelo chumbo. No mesmo ano, Vogt descreveu estas faixas nas extremidades de todos os ossos que crescem ativamente, incluindo entre $\hat{c l e s}$ as extremidades anteriores das costelas, próximo às articulações condrocostais. Em 1931, Caffey observou o mesmo aspecto nas costelas de um cão que morrera enyenenado pelo chumbo. Apesar disso, raramente a atenção do médico e, particularmente, do radiologista é voltada para outros ossos que não os dos membros, na pesquisa de sinais de envenenamento pelo chumbo.

Os AA. tiveram a oportunidade de observar 2 casos de envenenamento pelo chumbo em crianças, onde a presença das faixas de aumento de densidade foi verificada nas extremidades anteriores das costelas. Recordam os AA. que a possibilidade de envenenamento pelo chumbo poucas vêzes é admitida em casos de crianças com queixas vagas referentes ao abdome ou ao sistema nervoso, mesmo porque treqüentemente não há, na anamnese dêstes pacientes, referência à ingestão ou inalação, por parte dos pacientes, de tintas ou de objetos que tenham chumbo em sua composição. Geralmente, nestes pacientes a radiografia dos pulmões é praticada quase que infalìvelmente no intuito de esclarecer o diagnóstico, enquanto a radiografia das extremidades ósseas quase nunca é solicitada por falta de suspeita de envenenamento plúmbico.

Us AA. chamam a atenção para o fato de que as zonas de aumento de densidade nas metáfises dos ossos longos podem ser observadas em casos de crescimento normal, mas muito ativo do osso, assim como em casos de administração de grandes doses de vitamina $D$ ou na fase de cura do raquitismo, o que deve ser levado em consideração para efeito de diagnóstico diferencial.

\section{Pereira da Strva}

Variagõas da pressão intracrantana indicadas peio aspecto radiológico do crânio

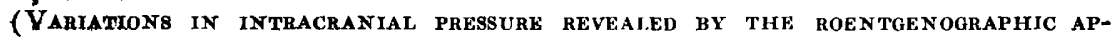
pearance of The skull). L. M. Davidoff. Emanuel Libman Anniversary Volumes, 1:357-362 (outubro) 1952 .

O A. estuda os aspectos craniográficos das variações de pressão intracraniana, documentando suas afirmações com a observação de um caso que teve oportunidade de seguir. Contesta a asserção de Mayer, que diz: "Nós sabemos que o aumento da pressâo pode remodelar a tábua interna do crânio em poucas semanas, mas, mesmo quando o aumento de pressão é transitório, seus efeitos sôbre o crânio permanecem durante longo tempo". Afirma o A. que Mayer não apresenta casos concretos que abonem sua afirmativa.

Lembra que cêrca de $80 \%$ de todos os tumores cerebrais em crianças se localizam no cerebelo, localização que determina precocemente hidrocefalia. Estes tumores determinam acentuadas modificações nos ossos do crânio, decorrentes da l:ipertensão craniana. Acha o A. que os casos de tumores cerebrais em crianças constituem o material ideal para o estudo dos efeitos do aumento de pressão sôbre os ossos cranianos.

No caso estudado pelo A., as modificações cranianas eram pronunciadas e, devido ao curso da moléstia, foi possível a tomada de vários craniogramas em épocas diferentes e em períodos diversos da evolução. Tratava-se de um paciente de 7 anos de idade que, um ano e meio antes de sua admissão ao hospital, se apresentou apático e desatento. Um ano depois, logo em seguida à amigdalectomia a 
que se submeteu, apresentou sinais de hipertensão craniana e de comprometimento cerebelar. $O$ exame radiográfico do crânio mostrou paredes delgadas, impressões digitais acentuadas, suturas disjuntas, principalmente a coronária, e atrofia da sela túrcica com desaparecimento do dorso e das clinóides posteriores. Foi submetido à operação, sendo encontrado grande cisto no cerebelo e um nódulo tumoral. Devido à vascularização da lesão, foi impossível remover todo o tumor. A anatomia patológica diagnosticou astrocitoma. Após a operação desapareceram cefaléia, vômitos, edema de papila e os sinais cerebclares. O craniograma praticado 6 meses depois evidenciou desaparecimento de todos os sinais de hipertensão craniana (as impressões digitais eram normais, as suturas tinham-se aproximado e a atrofia selar não era mais verificada). Dois meses mais tarde, novo craniograma, que mostrou o mesmo quadro. $O$ paciente continuou a passar bem, persistindo apenas a atrofia óptica secundária, sem redução acentuada da visão. Dez meses depois da intervenção surgiu novamente o quadro hipertensivo grave, com baixa acentuada da visão. As radiografias feitas evidenciaram novamente os sinais da hipertensão, com grande alargamento das suturas, atrofia selar acentuada, visualizando-se o "clip" da primeira intervenção deslocado pelo crescimento do tumor. Reoperação, sendo encontrado um grande cisto e um nódulo com cêrca de $5 \mathrm{~cm}$ de diâmetro, que foi excisado. Após a operação, desaparecimento dos sintomas hipertensivos e dos sinais cerebelares, permanecendo visão muito baixa. Radiografias praticadas 2 meses depois mostravam ainda sinais de hipertensão craniana. Finalmente, os craniogramas feitos 9 meses mais tarde evidenciavam outra vez melhora acentuada, atestada pelo apagamento das impressões digitais, pela menor disjunção das suturas e pela maior nitidez do dorso selar.

$O$ A. lembra que o desaparecimento dos sinais radiológicos da hipertensão craniana se processou muito mais lentamente após a segunda operação do que depois da primeira. Este fato levou o $\mathrm{A}$. a indagar se as modificações que ocorrem no osso corresponderiam à fibrose dos tecidos moles, que impede ou dificulta a volta d̀s condições normais. Acha o A. que o aumento da pressão intracraniana determina apenas descalcificação das estruturas ósseas sem destruição, pelo menos nos casos em que a hipertensão não atui por um longo tempo. Outro ponto focalizado pelo $A$. é o fato de que o edema de papila não é necessàriamente acompanhado de atrofia da selá túrcica; pelo menos foi o que verificou no caso observado, que procura explicar admitindo a formação de uma cicatriz na baínha do nervo óptico, a qual impediria a distensão do tecido neuro-retiniano pelo líquor.

\section{Pereira da Singa}

Cranidm bifidum occultum frontalis congênito e hereditário (Congenttal hereditary craniom bifidum occultum frontalis), R. J. Terrafranca e A. Tellis. Radiology, 61:60-65 (julho) 1953.

Os AA. relatam 3 casos de cranium bifidum occultum frontalis observados em membros da mesma família (mãe e dois filhos), sendo que em um dos casos a condição era acompanhada de espinha bifida cervical, lombar e sacra e de largos foramina parietalia. Em nenhum dos casos verificaram anomalias de desenvolvimento das clavículas, assim como não encontraram outras alterações ou anomalias cranianas, além das assinaladas. Clinicamente, havia a assinalar apenas a conformação do crânio, com bossas frontais proeminentes.

$O$ exame radiológico mostrou, no primeiro caso, criança de 6 anos, a existência de larga abertura na região mediof rontal, estando presente a sutura metópica acima e abaixo da fenestração. Essa paciente apresentava ainda largos foramina parietalia e espinha bífida em $\mathrm{C}_{5}, \mathrm{C}_{6}, \mathrm{C}_{7}, \mathrm{~L}_{5}$ e $\mathrm{S}_{1}$. No segundo caso, irmão da paciente anterior, com 14 anos de idade, havia uma abertura frontal de menores dimensões, estando presente também a sutura metópica e os foramina parietalia eram amplos, embora menores que no caso anterior. Finalmente, no terceíro caso, o 
exame radiológico mostrou pequena abertura frontal mediana, com espessamento das paredes do frontal a êsse nível; na região parietal havia pequenas depressões correspondendo aos foramina parietalia.

Discutindo a origem da anomalia em estudo, os AA. recordam que, de acôrdo com Schultz, o cranium bifidum occultum frontalis pode ser considerado como conseqüente à persistência de uma larga fontanela metópica, defeito de desenvolvimento de tendência hereditária.

$O$ cranium bifidum occultum frontalis se diferencia da disostose craniofacial porque não apresenta a assimetria do crânio e dos ossos faciais observados nessa disostose e se distingue da disostose cleidocraniana não só pela ausência de assimetrias craniofaciais, como pela ausência de defeitos nas clavículas.

\section{Pereira da Silva}

Disostose Cleidocraniana (Cleidocranial dysostosis). D. Eisen. Radiology, 61: 21-31 (julho) 1953.

Inicialmente, o A. lembra que a afecção se caracteriza pela transmissão hereditária, por hipoplasia ou mesmo aplasia das clavículas e pelo desenvolvimento exagerado do diâmetro transverso do crânio, com atraso da ossificação das fontanelas. Com relação à incidência dessa heredodistrofia, o A. cita o trabalho de Soule (1946), que fêz completa revisão bibliográfica do assunto, arrolando 100 publicações, onde se encontram relatados 323 casos de disostose cleidocraniana observados nas diversas partes do mundo; dêsses casos, 198 apresentam o caráter hereditário e 125 são esporádicos. Da revisão de Soule ressalta que a condição incide igualmente nos dois sexos.

Quanto à causa da afecção, é admitida a existência de um defeito no plasma germinativo paterno, defeito êsse que se localiza na área embrionária onde se agregam as primeiras células que irão dar origem ao sistema esquelético dos ossos membranosos, particularmente da clavícula e do crânio.

Us pacientes portadores da condição, em geral são de pequena estatura, apresentam o crânio desproporcionadamente volumoso, com diâmetro transverso predominante, mostrando bossas frontais e parietais proeminentes, face pequena, olhos largamente afastados e nariz deprimido em sua base. O tórax é achatado e a ausência ou o desenvolvimento rudimentar das clavículas permite aos pacientes a aproximação dos dois ombros anteriormente. Alterações na irrupção dos dentes podem ser observadas.

O A. apresenta, a seguir, as observações dos 4 casos estudados, acompanhadas de estudo radiológico pormenorizado de todo o esqueleto. Os pacientes estudados tinham idades de 3 e 16 meses, e 4 e 38 anos, sendo 2 do sexo feminino; um caso era esporádico e os outros 3 ocorriam em membros da mesma família. O A. observou em seus casos, além das modificações cranianas assinaladas e da hipoplasia das clavículas, numerosas outras alterações no sistema esquelético, acompanhadas de osteoporose e de atraso de ossificação.

\section{Pereira da Silva}

Alterações ósseas na miopatia (Osseous changes in myopatily). J. N. Walton e C. K. Wanrick. Brit. J. Radiol., 27:1-15 (janeiro) 1954.

Os AA. estudaram radiològicamente 38 casos de distrofia muscular progressiva (22 de forma Duchenne, 8 de forma fácio-escápulo-umeral e 8 de forma juvenil), 17 casos de miotonia atrófica e 6 de miotonia congênita. 
Nos pacientes com distrofia muscular, verificaram como achados constantes, nos casos precoces, rarefação nas extremidades dos ossos longos, alterações de desenvolvimento de ossos chatos e côxa valga; em estádios ulteriores da evolução da enfermidade, notaram escolioses, descalcificações difusas com perda das linhas de fôrça, por vêzes determinando graves distorçôes e desorganização do sistema esquelético; o grau dessas alterações ósseas estava sempre na dependência da precocidade do início da doença e da intensidade de seus sintomas. Alterações semelhantes foram assinaladas em membros atróficos de 4 pacientes que sofreram de paralisia infantil em tenra idade e em um caso de dermatomiosite. Os AA. concluem que as alterações ósseas na distrofia muscular não dependem de fatôres genéticos associados ou de uma osteomiopatia progressiva. Pelo contrário, devem ser atribuídas ao desuso ou à falta de estímulos sôbre os ossos devidos aos esforços desenvolvidos pelas inserções musculares ou ainda a posturas anômalas do corpo ou das extremidades como resultado de déficits motores e/ou contraturas.

$\mathrm{Na}$ moléstia de Steinert, verificaram algumas alterações apenas no crânio: a sela túrcica era significativamente menor e as tábuas cranianas bem mais grossas. Essas modificações ósseas se marcavam mais acentuadamente com a evolução da enfermidade. Em 6 casos de miotonia congênita e em 6 casos de colaterais (não afetados) dêsses pacientes, não registraram alterações ósseas importantes.

\section{R. Meicaragno Fitito}

Neuropatia diabética. Éstudo clínico de 150 casos (Diabetic neuropathy. A Ci.Inical. study of 150 cases). M. M. Martin. Brain, 76:594-624, 1953.

Desde 1798 são conhecidos os distúrbios neurológicos do diabetes e tal sua frequiência que, por certo tempo, pensou-se que o distúrbio metabólico estivesse na dependência de uma lesão do sistema nervoso central. Como a degeneração vascular periférica se acha comumente associada à desordem metabólica, muitos autores consideram-na como a causa da neuropatia diabética. Outros sugeriram que o diabetes, aumentando extraordinàriamente a utilização das vitaminas, conduzisse o organismo a uma avitaminose causadora de sintomas neurológicos. Diversos autores chamaram a atenção para a grande frequiência com que os distúrbios nervosos se seguem a longos períodos de descompensação metabólica; a neuropatia seria então atribuível a desordens do metabolismo próprias do diabete.

$O$ presente trabalho foi empreendido com a finalidade de elucidar as relações do diabetes com o desenvolvimento de distúrbios neurológicos, a importância da deficiência da vitamina $B_{1}$ e da degeneração vascular periférica, assim como estudar o comportamento do sistema nervoso autônomo. Com êsse objetivo, Martin selecionou 150 casos de neuropatia diabética, cujo diagnóstico era firmado por sinais ou sintomas nítidos: arreflexia, distúrbios da sensibilidade, déficit da motricidade, amiotrofias. Dêsses 150 casos, 108 (72\%) já tinham o diagnóstico de diabetes rotulado por ocasião do aparecimento dos distúrbios nervosos, enquanto que, nos $28 \%$ restantes, foi justamente a sintomatologia neurológica que conduziu ao diagnóstico de diabetes. $\mathrm{Em} 35 \%$ dos casos, verificou-se a existência de uma retinopatia diabética.

Cotejando os casos de neuropatia com os de diabetes que procuraram seu serviço hospitalar, Martin conclui que os casos de neurites periféricas ocorrem com grande frequêencia em pacientes com distúrbios do metabolismo dos hidratos de carbono, mas, na maioria dos casos, o comprometimento neurológico não se manifesta por qualquer sinal ou sintoma, os quais só são comuns nos pacientes em que o diabetes não é reconhecido precocemente ou nos casos que passan longos períodos de descompensação. A existência de uma neuropatia deve ser sempre suspeitada quando se trata de pacientes idosos com diabetes ligeiro mas de duração ignorada, particularmente em indivíduos com lesões tróficas nos pés. Martin acre- 
dita, em virtude da grande freqüência das neuropatias no diabetes, que as alterações nervosas devem ser atribuídas a distúrbios metabólicos, talvez a uma hiperglicemia prolongada. Como não há meios de se normalizar completamente o teor de glicose no sangue, compreende-se a possibilidade de se exteriorizar o quadro de neuropatia em diabéticos relativamente bem compensados. $O$ tratamento básico deve residir na tentativa da correção dos distúrbios metabólicos, sendo que outras terapêuticas têm apenas o valor de coadjuvantes. Martin investigou ainda a ação dos nervos vasomotores autônomos por meio da prova da sudorese, assim como o estado funcional da árvore arterial periférica por meio do oscilômetro Boulitte e pela vasodilatação derivada de injeções de Priscol. Em casos de diarréias diabéticas noturnas e de distúrbios vesicais, empregon, respectivamente, estudos radiológicos contrastados do tubo digestivo e a cistometria. A eventual aşão da carência de tiamina foi avaliada pelo teste da tolerância ao piruvato intravenoso. Através dêsses diversos métodos de investigação, o $\mathrm{A}$. conclui que os sinais e sintomas neurológicos do diabetes dependem apenas da participação de nervos periféricos. Os distúrbios vasomotores, as diarréias diabéticas, a impotência, as disfunções neurogênicas vesicais são devidas a alterações do sistema nervoso autônomo. As doenças vasculares periféricas e a avitaminose, aparentemente, não desempenham qualquer papel em sua patogênese.

\section{R. Melaragno Filio}

Armazenamento de cobre na degeneração hepatolenticular e molástias afins (Copper stolage in hepatolenticular degeneration and allied diseases). J. N. Cumings. Proc. Roy. Soc. Med. (Section of Neurology), 47:152-154 (fevereiro) 1954.

O A. relata as dosagens de cobre e aminoácidos na urina de 34 casos de doenças crônicas do sistema nervoso, a maioria com lesão do sistema extrapiramidal. As taxas encontradas foram muito inferiores às verificadas em 3 casos de degeneração hepatolenticular (DHL) com anel de Kayser-Fleischer (KF) e quadro clínico característico. Cinco outros casos foram examinados, destacando-se um de cirrose com episódios de confusão e tremor, sem KF; outro de cirrose, sem sinais neurológicos; os estudos bioquímicos foram normais em ambos. Noutro paciente, com tetraplegia e disartria, sem KF, portador de hepatite crôníca, havia nítida aminoacidúria (sem um aminoácido predominante à cromatografia), embora a excreção de cobre fôsse normal. Foram ainda examinados os cérebros de um caso de Parkinson, 2 de cirrose e um de DHL; apenas neste último foi encontrado armazenamento de cobre. O A. conclui que, nos casos típicos de DHL com KF, se encontra retenção de cobre no cérebro e aumento da excreção urinária dêsse metal è de aminoácidos; os outros casos, embora com quadro clínico semelhante, mas sem KF, não apresentam alterações bioquímicas na urina.

\section{H. Canelas}

Metabolismo da CReatina em paralisias de etiologia diversa, especialmente lesótes medulares (Creatine metabolism in paralyses due to variods causes, especially injuries to tile spinal cori)). L. J. Poliack, J. Bernsohn, S. W. Pyzik, J. R. Finki.e e H. Blestein. Arch. Neurol. a. Psychiat., 71:116-121 (janeiro) 1954.

Os AA. referem-se inicialmente ao fato de que a intolerância d̀ creatina é característica dos vários tipos de distrofia muscular, tendo, entretanto, sido descredita em outras condições; no setor das doenças neurológicas tem sido assinalada também na poliomielite anterior (tanto na fase aguda como nas sequielas graves). Dos pacientes observados, 14 apresentavam hemiplegia grave; 3, para- 
plegias de origem cerebral; 9 haviam sido submetidos a rizotomia anterior e 6 apresentavam sequielas graves de poliomielite anterior. Serviram êstes para o estudo comparativo das lesões nos neurônios motores central e periférico e daí deduziram fatos que foram relacionados com observações em pacientes com lesões em diferentes níveis da medula. Dêstes, 9 apresentavam lesão da medula cervical; 17, lesões não complicadas da medula torácica superior e média, e 11, lesões da medula torácica baixa e lombar, complicados com síndrome da cauda eqüina. Em todos os casos observados, os AA. são de opinião que a lesão produzia secção fisiológica completa e em alguns estava presente uma seç̧ão anatômica.

Concluem então que a intolerância à creatina só ocorre em lesões da medula, quando ao déficit motor está associada uma lesão do neurônio motor periférico; encontra-se nos casos de rizotomia anterior e em sequielas graves de poliomielite anterior; não é encontrada na hemiplegia grave ou paraplegia crural de origem cerebral; a quantidade de creatina excretada está em relação com a massa muscular atingida pela paralisia, seja de origem central ou periférica.

\section{A. Anghinah}

Estudo Sôbre a relação entre a aUgência de tonsilas E A INCidênCia da poi.ioM:ELITE BULBAR (A STUDY OF THE RELATIONSHIP OF THE ARSENCE OF tONSIIS TO the incidence of bulbar poliomyelitis). L. Weinstein, M. L. Vogel e $\mathbf{N}$. Weinstein, J. Pediat., 44:14-19 (janeiro) 1954.

A possível influência da tonsilectomia no desenvolvimento da poliomielite é assunto controvertido, tendo servido de matéria para diversos trabalhos experimentais. Vários autores acreditam que a tonsilectomia e a adenectomia, realizadas até 2 meses antes da infecção poliomielítica, predispõem ao comprometimento bulbar. Outros investigadores acham que a mera ausência de tonsilas e adenóides já seria suficiente para favorecer a localização bulbar do vírus.

No presente trabalho, Weinstein e col. reviram o registro de 800 observações de poliomielite, dos quais 300 correspondiam a pacientes com anígdalas e 500 a indivíduos prèviamente tonsilectomizados. Dêsse total de 800,85 desenvolveram a forma bulbar, sendo $12(14,1 \%)$ com amígdalas e $73(85,9 \%)$ tonsilectomizados; 80 apresentaram a forma bulbospinal, sendo $13(16,3 \%)$ com e 67 (83,7\%) sem amígdalas. Esses dados sugerem nitidamente que a ausência de tonsilas aurrenta a suscetibilidade para o comprometimento bulbar, mesmo nos casos em que a intervenção cirúrgica se processou muitos anos antes da exposição ao vírus.

A idade e o sexo não são fatôres importantes nessa suscetibilidade maior dos pacientes tonsilectomizados às formas kulbares da poliomielite. Os A A. concluem que os estudos sôbre os efeitos da amigdalectomia recente no aumento da incidência das formas bulbares da doença deven ser avaliados em função de uma suscetibilidade aumentada pela simples ausência dêsses órgãos linfóides.

\section{R. Melaragio Fitho}

Éstudos sôure a viremia Na Poliomielite. I: Isolamen'to do vínus da poliomielite

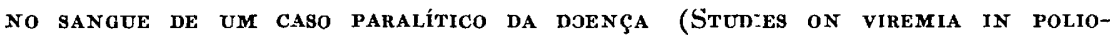

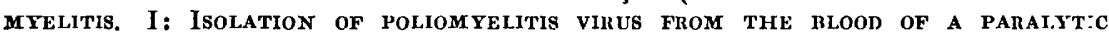
case of the disease). C. W. Jungeblut e E. J. Huenekens. J. Pediat., 44: 20-27 (janeiro) 1954.

Émbora o vírus da poliomielite tenha sido recentemente demonstrado na corrente sangüinea de animais de laboratório infectados experimentalmente, pouco se conhece sôbre a viremia na doença humana. A raridade do encontro do vírus ativo no sangue circulante tem sido atribuída à rápida formação de anticorpos 
homotípicos neutralizantes, os quais são reveláveis no sôro no início dos sintomas agudos. Os AA. exploraram então as possibilidades de isolar o vírus na fração celular do sangue, assim como no plasma. A tentativa de encontrar o vírus na porção celular do sangue se justifica pelo fato de que os vírus da poliomielite, quando em contacto com eritrócitos humanos, são adsorvidos pela superfície celular, formando uma sólida "unidade infecciosa". Nesse sentido, os AA. cstudaram amostras de sangue obtidas de 22 pacientes, durante a fase aguda da poliomielite paralítica, pesquisando a presença do vírus pela transferência a macacos. Puderam assim isolar o vírus ativo no sangue de uma paciente, extraído no dia de sua hospitalização, aproximadamente 3 dias após o estabelecimento dos primeiros sintomas clínicos. 'Tratava-se de uma mulher, no quarto mês de gravidez, que apresentava paralisias múltiplas quando a amostra de sangue foi extraída. $O$ vírus resultante era neutralizado pelo sôro da paciente e pela globulina $\gamma$ humana. Pelas provas serológicas, foi identificado como do tipo Brunhilde (tipo 1).

\section{R. Melaragno Finho}

Éstudos sôbre a viremia Na poliomielite. II: Adsorção in vitro da cepa JV do

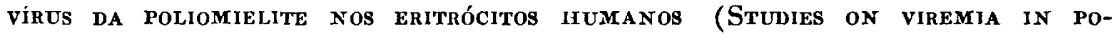
liomyelitis. II: ADSORPtion IN vitro of THE JV-STRAIN of polomyelitis vinus on human erythrocytes). C. W. Jungeblut. J. Pediat., 44:28-31 (janeiro) 1954.

Éstudos prévios haviam demonstrado que a cepa Leon (tipo III) do vírus da poliomielite era firmemente adsorvida pela superfície celular dos eritrócitos humanos, mas não pelos do coelho. Jungeblut se interessou em verificar se uma outra cepa do vírus poliomielítico, encontrável no sangue circulante (cepa JV, pertencente a um tipo serológico diferente: Brunhilde, tipo I) possuía propriedades semelhantes. Combinou então êsse vírus com eritrócitos humanos 0, preparados em condições experimentais adequadas e demonstrou a presença do vírus ativo no sedimento celular centrifugado, assim como no fluido sobrenadante. Quando êsses eritrócitos humanos, que haviam contraído o vírus in vitro, eram lavados três vêzes sucessivas, o vírus ativo já não era demonstrável no fluido sobrenadante, mas ainda se mantinha no sedimento dos eritrócitos centrifugados. Por outro lado, o exame do sangue de macacos infectados intramuscularmente demonstrou a presença do vírus ativo na fração plasmática mas não no sedimento eritrocítico. Kesultados positivos eram obtidos apenas no início da paralisia.

Não obstante essas experiências se encontrarem ainda em fase preliminar, algumas suposições podem ser sugeridas no mecanismo da viremia. De fato, se o vírus é potencialmente capaz de infectar evitrócitos humanos, pode-se supor que $a$ invasão da corrente sangüínea represente uma reação tissular primária e não mero fenômeno circulatório secundário. De qualquer modo, mesmo que o sangue não seja sede de multiplicação do vírus, a possibilidade dêle transportá-lo fornece à corrente sangüínea um provável papel de importância na patogenia da doença.

\section{R. Melaragno Filho}

Éstudos eletrencefalográftcos de CRIANÇas com lesões intracranianas adquiridas No PARTO (ELECTROENCEPHalographic STUdIES OF INFANTS AND CHILDREN who acquined intracranjal injuries at birth). O. Morstad e B. KaAda. Neurology, 3:544-549 (julho) 1953.

Um grupo de 201 pacientes, de 3 a 21 anos de idade, com história definida de traumatismo on asfixia de parto, foi cuidadosamente estudado sob o ponto de vista neuropsiquiátrico. Dêsses pacientes, 137 foram tidos cono normais. Em 54 
pacientes do grupo total foi feito estudo eletrencefalográfico, e êstes constituem o motivo do presente trabalho. No primeiro subgrupo de 11 pacientes, clinicamente normais, o EEG foi normal em 10 e em um apresentou descargas focais. No segundo subgrupo, totalizando 21 pacientes com história de repetidas crises convulsivas, o EEG foi normal em 6, mostrou descargas focais em $9 \mathrm{e} \mathrm{em} 6$ havia distúrbios difusos constantes. No terceiro subgrupo, com 19 pacientes que evidenciavam sinais de deficiência mental, sòmente um apresentou EEG normal, enquanto 7 mostraram desordens difusas e 11, sinais de atividade focal. A topografia dos focos lesionais, muito bem apresentada em esquemas bastante objetivos, evidencia predominância para a sede temporoparietal. Digno de menção, ainda, é o fato de, entre 20 casos lesionais, o foco se situar no hemisfério esquerdo em 15. A sede predominante temporoparietal dos focos é explicada pelo fato, já anteriormente demonstrado por outros, de que as áreas corticais temporoparietoccipitais são mais sensíveis à anóxia. Para a sensível predominância dos focos no hemisfèrio esquerdo, os AA. não encontram explicação plausível. Não foi possível o estabelecimento de correlação entre a sede do foco lesional e o tipo de apresentação no parto.

P. Pinto Puro

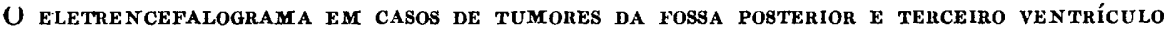
('IHE ELECTROENCEPHALOGRAM IN CASES OF TUMORS OF THE POSTERIOR FOSBA AND third ventricle). D. Daly, J. L. Whelan, R. G. Bickford e C. S. Mac Carty. EEG a. Clin. Neurophysiol,, 5:203-216, 1953.

Após breve referência à literatura sôbre o assunto, os AA. apresentam seus achados eletrencefalográficos em 66 casos de tumores de fossa posterior, 12 de tumor de terceiro ventrículo e 9 de hidrocefalia obstrutiva, todos cirirgicamente verificados, exceção feita a 6 casos de tumor em que o diagnóstico foi realizado com auxílio da ventriculografia. As alterações foram agrupadas em rítmicas (disritmias) e arrítmicas, estas correspondendo ao que os autores em geral denominam de ondas delta.

Não foi possível, pelo EEG, distinguir sede ou natureza das lesões, tanto que tumores do terceiro ventrículo deram alterações bilaterais e lateralizadas, o mesmo ocorrendo com os tumores do hemisfério cerebelar. Os AA. chamam a atenção para o fato de as arritmias serem pouco influenciadas pela abertura e fechamento dos olhos e ainda pela hiperpnia, sendo grande a influência dêstes procedimentos nos casos em que apareceram disritmias.

Us AA. discutem a gênese das disritmias, dando grande importância à hipertensão no terceiro ventrículo. Tal afirmação é baseada nos seguintes dados objetivos: dos 74 , casos com sinais de hipertensão ventricular (papiledema ou dilatação ventricular evidenciada pela ventriculografia), $82 \%$ dos casos mostraram EEG anormal, ao passo que, em 13 casos sem papiledema, apenas $38 \%$ tiveram eletrencefalograma anormal. A idade do paciente e a agudeza do processo agem como fatồres coadjuvantes. As alterações eletrencefalográficas foram tanto mais freqüentes quanto mais jovem o paciente e quanto mais agudo o processo.

\section{E. ZUKenMAN}

O eletrencefalograma em casos de hemorragia subaracnóimea (The electroencephalogram in cases of subaracnoid haemorrhage). J. H. D. Millar. EeG a. Clin. Neurophysiol., 5:165-168, 1953.

Após breve revisão da literatura sôbre o assunto, o A. apresenta seu material de 26 casos: 15 de aneurisma congênito e um de aneurisma arteriovenoso confir- 
mados pela arteriografia, e os demais clinicamente suspeitos de aneurisma com o quadro de hemorragia subaracnóidea. Dos 16 casos confirmados, 13 apresentaram alterações eletrencefalográficas assimétricas, mais intensas no hemisfério cerebral sede do aneurisma rôto. Ém 15 casos com sinais clínicos focais, as alterações do EEG foram concordantes em 14. As anormalidades difusas coincidiram, na grande maioria dos casos, com perturbações da consciência. $O$ autor notou piora progressiva clínica e eletrencefalográfica em 5 casos suspeitos e posteriormente confirmados de hematomas.

\section{E. ZUKLRMAN}

ACHados eletrencefalográficos No hematoma subdural; Revisão de 45 casos (Electroencephalographic FINDINGS associated With SUBdURAL HEMATOMA; REview of 45 cases). E. A. Rodin, R. G. Bickford e H. J. Sviex. A rch. Neurol. a. Psychiat., 69:743-755 (junho) 1953.

Após revisão da literatura, os AA. apresentam os resultados do estudo eletrencefalográfico de 45 casos de hematoma cirùrgicamente confirmados e nos quais não foi comprovada laceração cerebral. Dêstes, 7 casos foram examinados entre $07^{\circ}$ ao $14^{\circ}$ dia do acidente causal, 5 entre o $14^{\circ}$ e $30^{\circ}$ dia e 35 entre 2 a 3 meses; portanto, a maioria dos casos foi de hematoma crônico.

No grupo de crianças os resultados foram em geral duvidosos e de difícil interpretação, ao passo que, no grupo de adolescentes e adultos, o EEG conseguiu localização correta em $55,9 \%$, não localizou em $29,4 \%$ e forneceu localização incorreta em $14,7 \%$ dos casos.

$O$ elemento de maior valor localizador foi o foco de ondas $\delta$. Nos casos de hematoma bilateral o lado mais comprometido ou de hematoma maior foi aquèle no qual as ondas $\delta$ eram mais lentas. A fotostimulação não foi útil na determinação do lado em que se achava o hematoma. Foi grande o número de casos que apresentou disritmias, em relação com possível comprometimento do sistema reticular.

$\mathrm{Na}$ maioria dos casos em que havia depressão de ritmo, esta persistiu durante 11 dias em média após a intervenção cirúrgica, o que leva a crer que a exıstência de líqüido entre o córtex e os eletrodos por si só não explica tal alteração, devendo esta correr por conta de distúrbios metabólicos locais associados ao trauma. Ouiro elemento de interêsse, e que contraria o que se tem observado na literatura, é o fato da "depressão" não ocorrer apenas em áreas posteriores, aparecendo também em áreas anteriores.

\section{E. ZUKF.RMAN}

Resposta de Focos ePILEPTógenos FXPerimentais ao Cardiazol intravenoso e tópico (RESPONSE OF EXPERIMENTAL EPILEPTIC FOCI TO INTRAVENOUS AND TOPICAL METRAzol). H. C. Johnson e A. E. Walker. EEG a. Clin. Neurophysiol., 4:131$139,1953$.

A injeção intravenosa de $0,2 \mathrm{ml}$ de cardiazol em 12 macacos nã') prodiuziu crises convulsivas, ao passo que, nas preparaçôes pelo método de Kopeloff, entre a e 8 meses, obtiveram maior número de crises convulsivas, portanto, maior atividade focal. Neste material assim preparado, o cardiazol desencadeou ao eletrocorticograma alterações focais, intensificando as pré-existentes.

Ĺm seguida, os AA. estudam o efeito da aplicação tópica do cardiazol, em córtex normal de macacos e em córtex em que se observou foco convulsiógeno. Notaram que, em córtex normal, o cardiazol tópico desencadeia descargas focais 2 a 3 minutos após a aplicação, por vêzes em áreas homólogas à aplicação, no hemisfério oposto. Éstas descargas persistiram, em média, de 5 a 10 minutos. $O$ car- 
diazol, empregado em solução a 10\%, só determinou as alterações acima citadas até a diluição de 1/16. A aplicação tópica aos focos convulsiógenos evidenciou descargas focais muito mais duradouras que aquelas do córtex normal; esta ativação verificou-se com soluções muito diluídas até $1 / 64$, indicando tal fato que os casos em que existiam focos eram muito mais sensíveis ao cardiazol; as alterações focais nestes macacos con facilidade se difundiam para áreas vizinhas e se generalizavam.

Us autores concluem que: o cardiazol intravenoso em macacos epilépticos desencadeia alterações eletrencefalográficas ou acentua as pré-existentes; o limiar convulsivo. é mais baixo em macacos epilépticos que nos normais; o foco epiléptico é mais sensível à aplicação tópica do cardiazol que as demais áreas do córtex de um mesmo animal, ou que o córtex de animais normais.

\section{E. ZUKERMAN}

Evolução tardia, clínica e eletrencefalográfica, de quatro casos de hiemisfeneotomia total (Evolución tardia, clínica e electroencefalográfica, de cuatro casos de hemisferectomia cerebral). S. Obrador e L. M. H. Larramendi. Rev. de Oto-Neuro-Oftalmol. y Neurocir., 10:389-394 (novembro-dezembro) 1953.

Os AA. resumem a evolução tardia de 4 doentes que foram seguidos por períodos de tempo variável de três ancs e meio a um ano e neio depois de ojerados.

As etiologias e idade do início da lesão eram as seguintes: caso 1 - "ataque cerebral" de causa desconhecida, aos 3 anos de idade; operada aos 17; caso 2 meningite aos 5 anos; operada aos 7 ; caso 3 - trauma de parto; operado aos 11; caso 4- moléstia infecciosa aos 9 meses; operado aos 29 anos. Todos os pacientes aprcsentavam o quadro típico de hemiplegia infantil com atrofia e espaticidade. $O$ nível mental era muito baixo e existia também, em todos, irritabilidade e tendências agresijivas, com episódios periódicos de conduta anormal. As manitestações epilépticas eram frequientes em todos os casos e resistentes à terapêutica. Nos traçados eletrencefalográficos pré-operatórios havia atividade lenta bilateral e focos de descargas em ponta, mais nítidos habitualmente no henaisfério afetado. A pncumencefalografia mcstrava graus diversos de atrofia; o ventrículo contralateral à lesão estava moderadamente aumentado em 2 casos e normal nos outros 2.

A hemisferectomia foi feita sob anestesia geral, com exceção do caso 4, em que se usou anestesia local e se conseguiu o eletrocorticograma; é interessante assinalar que não apareceu modificação da consciência com a extirpação de todo o córtex do hemisfério. 'Três vêzes foi extirpado o hemisfério direito e uma vez o esquerdo.

O quadro neurológico pós-operatório residual não se modificou em relação à hemiplegia infantil pré-operatória. Houve aparecimento de hemianopsia nomónima. A inervação motora ipsilateral foi suficiente para a marcha, ainda que houvesse paralisia do pé. $O$ braço ficou muito mais afetado do que a perna $\mathrm{e} a$ motilidade limitou-se ao ombro e ao cotovêlo. A paresia da face foi maior ncs movimentos emocionais. Persistiu também bastante integração sensitiva ipsilateral e nos pacientes maiores se observou certo reconhecimento, não sòmente dos estímulos elersentares, mas também da vibração, posição e símbolos escritos na pele. Assim como para a motricidade, foi mais afetado o braço do que a perna e a face.

A conduta e a mentalidade melhoraram. A irritabilidade e a agressividade desapareceram, havendo maior cooperação de parte dos doentes. Fm relação à epilepsia, no caso 1 não houve mais crises 3 anos e meio depois da operação, tendo-se normalizado a atividade elétrica do hemisfério residual. Os 3 outros doentes meIhoraram muito, apresentando sòmente algumas crises ocasionais $\mathrm{cm}$ contraste com os frequientes ataques pré-operatórios. As ausências desapareceram e o caso 2 só teve 16 crises em mais de 2 anos desde a operação, o caso 3 apresentou 5 ataques 
em 2 anos e o caso 4, 17 crises em 1 ano e meio de curso pós-operatório. $O$ eletrencefalograma dêstes casos também melhorou, persistindo anormalidades de baixa trequiência e algumas descargas em ponta no hemisfério residual.

C. De Luccia

Éstudos eletrográficos No HOMEM E No ANIMAL das descargas EPILÉpticas ditas "PSicomotoras" (ETUdes Électrographiques ChEz L'HOMME ET chez L'ANiMAL des décharges ḱpileptiques dites "psychomotrices"). H. Gastaut, R. Naquet, R. Vigounoux, A. Roger e M. Badier. Rev. Neurol., 88:310-354, 1953.

Em extenso trabalho clínico-eletrencefalográfico e experimental, os AA. fazem uma análise crítica da epilepsia $\mathrm{Psm}$, especialmente em relação ao ponto de origem de sua descarga focal. $O$ estudo clínico é baseado em 300 pacientes, com diagnóstico clínico e eletrencefalográfico de epilepsia Psm, tendo sido feitos no minimo três traçados eletrencefalográficos e tendo sido observada a crise clínica, espontânea ou provocada (cardiazol). Seus achados eletrencefalográficos são estudados minuciosamente quer quanto à forma e à cronologia, como à topografia de projeção das descargas elétricas interparoxísticas e paroxísticas. Nesse capítulo chama a atenção a existência de 29 casos em que não apareceram descargas interparoxísticas e, quanto às descargas paroxísticas, em $29 \%$ dos casos não houve manifestação elétrica concomitante com a crise clínica. Os AA. argumentam com resultados experimentais, em que há possibilidade do foco ser oculto, profundo, e não se propagar aos eletrodos da superfície.

Os esiudos eletrocorticográficos são relativos a 45 pacientes que foram à cirurgia, e êstes naturalmente são mais uniformes, pois sòmente pacientes com foco restrito foram levados à mesa operatória. Lim $24 \%$ dos casos as descargas se sediaram na face lateral do lobo temporal, em $47 \%$ na face inferomedial, em $29 \%$ elas tomaram ao mesmo tempo as faces inferomedial e lateral dêsse lobo. Isto mostra que, em $73 \%$ dos casos, o foco não é da convexidade e sim da profundidade dêsse lobo.

Depois de descrever os tipos de descargas primárias e secundárias, e de fazer correlações eletranatômicas, os AA. discriminam seus resultados pós-operatórios, que podem ser sintetizados em: a ablação do polo temporal deu os melhores resultados elétricos e clínicos, enquanto que a girectomia deu maus resultados em ambos os sentidos. Em certos casos de descargas bitemporais a ablação sòmente do temporal mais afetado pôde fazer desaparecer as descargas no temporal do lado oposto.

Seus resultados experimentais se baseiam no estudo de 11 gatos, nos quais conseguiram provocar foco convulsiógeno com injeção subcortical de creme de alumínio, tendo realizado estudo clínico e eletrográfico interparoxístico e paroxístico. E' de interêsse sua análise topográfica, em esquemas anatômicos, das corrclações entre foco, projeção na corticalidade e tipo de crise. Em síntese são: 1 - foco no lobo olfativo, hipocampo, amígdala, acarreta descargas no uncus, ínsula, ponta do lobo temporal e região orbitária posterior, e clìnicamente as crises são $P_{\text {sm }}$ (fenômenos alimentares, afetivos e "reação de desvio"); 2 - foco no subtálamo e tegmento mesencefálico projeta-se no mesmo território órbito-ínsulo-uncus-temporal; as crises clínicas se avizinham das precedentes, mas não são espontâneas, e sim, necessitam ser provocadas pelo cardiazol (em doses mínimas, não eficientes para o animal testemunha); 3 - foco no pulvinar, núcleos lateral e posterior do tálamo, projetam-se no córtex temporal posterior e parietal, e foco no pulvinar e núcleo geniculado provoca projeção no lobo occipital; 4-lesões subcorticais estritamente unilaterais podem provocar projeção em ambos hemisférios, concomitantes ou independentes, sendo que as descargas corticais contralaterais podem persistir semanas após ablação do foco subcortical experimental, enquanto que as ipsilaterais desaparecem logo com êle. As lesões nas regiões pré-óptica, do sep̣to, tá- 
lamo anterior e hipotálamo anterior acarretaram precoce morte do animal, pelo que não têm delas observações.

Na discussão dêsses resultados, os AA. fazem um paralelo com os dados conhecidos da literatura e chegam a conclusões que, embora apresentadas ainda sob reserva, os levaram a classificar as epilepsias psicomotoras em: a) epilepsia Psm temporal pròpriamente dita (rara, lesão temporal superficial, com descargas circunscritas no EEG e manifestações clínicas de ilusão e alucinação, visual ou auditiva); b) epilepsia Psm hipocampal (a mais freqüente, por lesão da ponta do lobo temporal, hipocampo, todo rinencéfalo e áreas insulares, com descarga ipsilateral ou bilateral no EEG, projeção na região anterior temporal sôbre o crânio, cuja manifestação clínica é mastigação, salivação, sensação epigástrica, faríngea ou abdominal, com confusão mental e fenômenos de automatismo, a expressão clínica intercrises se caracterizando por distúrbios do caráter e do comportamento, e cuja etiologia está em tôdas condições capazes de provocar esclerose atrófica de região hipocâmpica: hérnia hipocampal natal, de Penfield, contusão cerebral por contragolpe nos traumatismos crânio-encefálicos fechados, meningites e meningoencefalites das cisternas silviana e quiasmática; c) epilepsia Psm diencefálica (frequiência intermediária entre as precedentes) dependente de lesão do tálamo, hipotálamo ou subtálamo e tegmento, cuja expressão no EEG são descargas difusas, por vêzes bilaterais, e que clinicamente se apresentam por crises de distúrbios impulsivos, por vêzes violentos, e reações afetivas, e que nas fases interparoxísticas se apresentam com quadro verdadeiramente psicossomático; sua etiologia é representada pelas encefalites, em especial aquelas decorrentes das moléstias eruptivas da infância (rubéola).

Merece atenção a documentação farta apresentada por Gastaut e col.. Entretanto, sua generalização, indo a focos em regiōes completamente diversas las do lobo temporal e do rinencéfalo até aqui conhecidas como responsáveis pela epilepsia Psm, a nosso ver não tem razão de ser, pois engloba síndromes clínicas e eletrencefalográficas inteiramente diversas. Além disso, sua documentação clínica com correlação anátomo-elétrica comprovada diz respeito sòmente a focos temporais localizados; logo, não poderão com ela tirar conclusões sôbre os demais observados, já que não possuem elementos anatômicos de comprovação do fuco lesional. Por outro lado, sua documentação experimental mostra certo número de focos temporais e rinencefálicos com sindrome clínica semelhante à epilepsia Psm e com projeção eletrográfica idêntica a ela, mas nos demais tocos talâmicos, tegmentais, etc., a síndrome clínica é tôda outra que a do Psm e a projeção eletrencefalográfica se mostra também inteiramente diferente. Como relacionar tais elementos para conclusões em comum?

\section{P. Pinto Pupo}

'T'ríplice contração do músculo estriado e tríplice cronaxia do músculo e de seu Nervo Motor ('T'riple contraction du Muscle strié et triple chronaxie du MUSCle ET de SON Nerf Motedr). G. E A. Bourguignon. Rev. Neurol., 82: 114. (fevereiro) 1950.

Pela excitação bipolar é possível registrar isoladamente o miograma de feixes de condução diferente e medir sua cronaxia. Foi verificado, no coelho e no cão, que os feixes musculares de condução rápida têm a mesma cronaxia do ponto motor e do nervo, os de condução média uma cronaxia 10 vêzes maior e os de condução lenta 100 vêzes maior, apresentando cada um dêles, características histológicas e químicas próprias. No homem, a excitação do bíceps com um pequeno eletrodo, permitiu decompor o ponto motor em três pontos vizinhos: o primeiro, cuja excitação provoca contrações vivas numa região do músculo, o segundo, que provoca contrações lentas noutra região e o terceiro, que determina contrações fran- 
camente lentas noutra região; correspondem respectivamente à cronaxia dos feixes de condução rápida, média e lenta. Quando se utiliza o cletrodo habitual, muito grande, os feixes de condução rápida primeiramente excitados, determinar contrações rápidas que mascaram as contrações lentas. Pela filmagem, foi possível demonstrar que essas contrações se dão em zonas bem determinadas e constantes e que a forma da contração de um feixe é independente da duração da excitação. Os AA. assinalam a importância da topografia dos pontos motores e dos feixes de condução diferentes, pois poder-se-ia admitir fenômenos de degeneração quando na realidade se trata de feixes de condução lenta, normais. Êste trabalho permite demonstrar a existência de três espécies de feixes no músculo estriado normal $\mathrm{e}$ a descoberta de três cronaxias no ponto motor e no nervo prova categòricamente a lei do isocronismo neuro-muscular, encerrando definitivamente as discussões sôbre o assunto.

W. Brotro

Tratamento chrúrgico de aneurismas da artérla comunicante anterior (Surgical treatment of aneurysms of the anterior communicating artery). G. Nori.ín e A. S. Barnum. J. Neurosurg., 10:634-650 (novembro) 1953.

$\mathrm{Na}$ terapêutica cirúrgica dos aneurismas da artéria comunicante anterior, a mortalidade diminuiu sensivelmente e a tendência atual é admitir a agressão operatória ao aneurisma como o tratamento de escolha, embora o tipo de processo cirúrgico varie com a preferência dos diversos autores.

US AA. consideram o aneurisma da artéria comunicante anterior como um problema cirúrgico especial dentro do tratamento operatório dos aneurismas intracranianos. No presente trabalho, registram 26 casos oriundos da artéria comunicante anterior, internados em sua clínica até abril de 1952. Dêsses pacientes, 24 foram operados por um ou outro processo cirúrgico e de seus resultados os AA. procuram postular quais os melhores processos de acesso e de agressão à malformação vascular. A incidência de aneurismas intracranianos na população geral foi avaliada em cêrca de $1 \%$ e, no conjunto dos casos registrados de aneurismas cerebrais, os da comunicante anterior representam aproximadamente de 20 a $25 \%$. Nos 24 casos tratados cirùrgicamente houve duàs mortes operatórias e uma terceira subsequiente a hemorragia subaracnóidea em um caso no qual o gelfoam havia sido aplicado contra o saco aneurismático. Um quarto paciente faleceu de hemorragia subaracnóidea um ano e meio mais tarde, sendo um dos casos que se internara quando não havia ainda suficiente experiência cirúrgica e no qual foi feita a craniotomia mas não se tocara no aneurisma. Devido ao curto lapso de tempo decorrido desde a operação dos últimos casos, conclusões definitivas não podem ainda ser assinaladas. De 15 pacientes tratados pela ligadura do colo do aneurisna, 14 sobreviveram à operação e nenhum dêles evidenciou qualquer sinal de sangramento ulterior; 5 voltaram ao trabalho; 2 que haviam sof rido de distúrbios visuais, meIhoraram consideràvelmente após a intervenção; 5 tiveram alta sem sinais neurológicos, embora até o momento não houvessem ainda reassunido suas atividades. De 2 casos com hemiplegia prévia à operação, um estava melhorado e o outro não se alterara. Ėm um caso, a hemiplegia surgiu alguns dias após a intervenção, talvez devido à formação de um trombo. Os AA. insistem sôbre a necessidade de um exame angiográfico prèviamente a qualquer intervenção. Preconizam a agressão direta ao aneurisma, com ligadura de seu colo, como processo cirúrgico de escolha.

R. Meicaragio Filho 
O tratamento de aNeurismas na artéria carótida interna por ligadura arterial

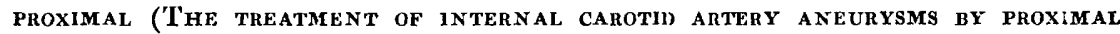
arterial ligation. A follow-up study). S. P. W. Black e W. J. German. J. Neurosurg., 10:590-601 (novembro) 1953.

O\&. aneurismas da artéria carótida interna, quer na porção cavernosa, quer na cerehral, foram tratados no Departamento de Cirurgia da Yale University School of Medicine, nos últimos 16 anos, pela ligadura proximal da artéria. Neste trabalho, os AA. fizeram uma revisão clínica de suas experiências e avaliaram alguns cos fatôres hemodinâmicos concernentes a êste processo terapêutico. São 35 casos, cujo follow-up pôde ser determinado: 8 faleceram de causas diversas e 27 ainda viviam. Dêsses casos, 9 eram de sede cavernosa: um faleceu de periarterite nodosa e 8 viviam por ocasião do estudo. Dos 26 casos de aneurismas na porção cerebral, 7 faleceram e 19 ainda sobreviviam. A operação em si era, $\epsilon m$ geral, benigna; os AA. não advogam a ligadura cervical da carótida para o tratamento de aneurismas de outras artérias cerebrais, especialmente as artérias comunirantes. Finalmente, procuram justificar, em bases hemodinâmicas, a realização da ligadura da artéria carótida.

R. Melaragno Filug

I Ndicações cirúrgicas nas epilepsias chamadas "Temporais" (Indications chirurgicales dans les Épilepsies dites "temporales"). J. Guillaume, G. Mazars e Mмe. Y. Mazars. Rev. Neurol., 88:461-501, 1953.

Em extenso e meticuloso trabalho os AA. fazem uma revisão do assunto e apresentam seus resultados pessoais.

De início situam o problema das epilepsias cirúrgicas, restringindo-as àquelas em que a indicação operatória é feita à base da semiologia própria da epilepsia e visa diretamente o desaparecimento das crises. Afastam, portanto, dêste quadro, todos aquêles casos de tunıres da região, verificados pela semiologia clínicu-radiológica.

Nos seus primeiros capítulos fazem a história do conceito clínico e eletrencefalográfico das chamadas "epilepsias temporais" e discuten as bases de ordem anatômica, cirúrgica, experimental e eletrencefalográfica sôbre as quais repousa tal conçeito, chamando a atenção para os perigos da limitação injustificada ou da extensão excessiva dêste grupo, como querem alguns autores. Sòmente com restrição às epilepsias causadas por foco em áreas têmporo-ínsulo-hipocâmpicas, as quais têm quadro clínico também delimitado, podem considerar as epilepsias temporais suscetíveis de tratamento cirúrgico.

No quarto capítulo discutem o diagnóstico, analisando os elementos fornecidos: 1 - pela radiologia (assimetrias cranianas, em particular da fossa temporal; imagens ventriculográficas anormais, imagens arteriográficas); 2 - os sinais neuropsiquiátricos, associados (discreta paresia facial, hemianopsia homônima ou certos quadros de hipomania, de agressividade ou negativis.no, observados habitualmente nestes casos); 3 - os elementos fornecidos pela própria crise (auras auditivas, vertiginosas ou crises alucinatórias olfativas, distúrbios de tipo afásico, crises de parestesias no hemicorpo; auras epigástricas, abdominais ou digestivas, e automatismo de tipo psicomotor; as crises generalizadas do início podem ser consequientes a foco temporal, mas o diagnóstico então será puramente cletrencefalográfico); 4 - as características eletrencefalográticas, seja durante, seja no intervalo das crises.

Nos capítulos seguintes analisam os resultados cirúrgicos da epilepsia nos diversos centros em que ela se desenvolveu, assim como seus resultados próprios, neste particular avaliando em seus mínimos detalhes a influência da natureza ana- 
tômica das lesões, da idade dos pacientes, da sede do foco epileptógeno e da extensão de sua ressecção, assim como os fatôres responsáveis pelos fracassos parciais ou totais, as seqüelas operatórias e problemas de ordem técnica. A experiência dos AA. é de 125 casos operados, dos quais 83 de epilepsia temporal. Nesta análise apresentam 72 dêstes casos, seguidos durante 6 meses a 4 anos, e seus resultados são configurados em quadros analíticos bastante criteriosos.

A opinião por êles expendida é bastante favorável. Da análise da literatura verificaram que o tratamento cirúrgico é suscetível de propiciar a supressão das crises em metade dos operados e melhoria útil em mais da metade dos demais. Us resultados próprios se mostram excelentes em mais de $70 \%$ dos casos, considerando-se como tais os pacientes catalogados em seus quatro primeiros grupos de avaliação pós-operatória: $1^{\circ}$ grupo - supressão total das crises, sem medicamentos; $2^{9}$ grupo - supressão total das crises, com dose míni:na de gardenal; $3^{\circ}$ grupo - supressão total das crisas, mas persistência de sequiela neurológica compativel com boa readaptação social; $4^{\circ}$ grupo - persistência de uma a duas crises por ano.

E' de notar que até o momento atual têm sido levados à mesa operatória sòmente os casos piores: os absolutamente rebeldes ao tratamento medicamentoso, os intolerantes aos medicamentos, os que apresentam perturbações de caráter $e$ de conduta que os impedem de adaptação ao ambiente social. Os AA. propugnam péla extensão desta indicação operatória a outros pacientes que não nestes estados extremos, lembrando principalmente o grande interêsse médico de se poder reduzir ao mínimo, ou mesmo suprimir totalmente, a terapêutica medicamentosa, o que, em certos pacientes, traz melhoria sensível no estado emocional, na atividade psíquica e mesmo na sua adaptação social. Ao lado dêsses elementos devem ser levados em conta outros fatôres, como o mínimo risco operatório (nenhum óbito nos 68 casos de Penfield e nos 125 dos AA.), o fato de que as seqüelas neurológicas também são bastante reduzidas se se tem em mente evitá-las ao máximo durante o ato operatório (a hemiplegia é passageira quando se evita lesar a cápsula interna; os distúrbios afásicos quando não se procede à extirpação de áreas corticais temporais tão logo êles apareçam; as henianopsias, muito reduzidas, são pràticamente desprezíveis). A existência de certos tumores de longa evolução e que passam despercebidos aos meios semiológicos comuns (8 entre seus 72 casos), cuja extirpação precoce trará o mais alto benefício aos pacientes, deve também pesar em favor da escolha da terapêutica cirúrgica em muitos casos.

\title{
P. Pinto Pupo
}

\begin{abstract}
Valor do bloqueio do gânglio estrelado no icto (Is stellate ganglion block of value in stroke?). J. E. Ruben e R. A. Mayer. J.A.M.A., 153:1002-1004 (novembro) 1953.
\end{abstract}

Ém virtude dos resultados contraditórios apresentados na literatura sôbre a ação do bloqueio do gânglio estrelado nos acidentes vasculares cerebrais, os AA. estudam os resultados obtidos em 58 enfermos com história de icto ceribbral. Os enfermos foram divididos em dois grupos, de acôrdo com a duração da moléstia. Us pacientes submetidos ao bloqueio durante o primeiro mês após a instalação dos sintomas clínicos do acidente vascular cerebral foram considerados como casos agudos e aquêles tratados depois de decorrido o primeiro mês do aparecimento dos sinais clínicos foram chamados de casos crônicos. Os bloqueios foram feitos com procaína a $1 \%$ ou droga similar, usando-se a via anterior para atingir o gânglio. Foram observados 58 enfermos, dos quais 43 foram considerados como casos agudos e 15, crônicos. No grupo de casos agudos, foi encontrada melhora evidente $\mathrm{em} 17$ casos dentre 25 que apresentavam trombose certbral, 4 malhoras em 6 enfermos com embolia, melhora evidente em todos os 5 casos de espasmo 
cerebral; não houve alteração do estado clínico de um paciente com hemorragia e de 5 casos com encefalomalácia. No total de 43 casos agudos houve melhora acentuada em $26(60,4 \%) ; 9$ pacientes vieram a falecer e 8 tiveram seu estado inalterado. No grupo de casos crônicos, houve melhora em apenas 4 pacientes (todos com história de trombose) dentre um total de 15 enfermos tratados pelo bloqueio.

Os AA. acentuam que a melhora clínica sempre ocorreu alguns minutos após o aparecimento da síndrome de Claude Bernard-Horner conseqüente ao bloqueio do estrelado, o que afastaria a possibilidade de uma remissão espontânea do quadro clínico. Os AA. concluem que o bloqueio do gânglio estrelado é um método inócuo quando feito por médico experiente, e que representa o melhor tratamento atual para os casos de trombose, embolia e espasmo cerebrais.

\section{J. Armbrust-Figueiredo}

Estudo comparativo dos resultados obtidos com a topectomia e a lobotomia preFRONTAIS (ÉTUde COMPARATIVE DES RÉSULTATS DE IA TOPECTOMIE ET DE LA LOBOtomie préfrontales). P. Goinard, P. Descuns e H. Garké. Rev. Neurol., 88: $515-530,1953$.

Os AA. comparam os resultados obtidos em 101 pacientes com distúrbios mentais, dos quais 3 foram reoperados, e nos quais foram feitas 16 topectomias, segundo a técnica de Pool, e 88 lobotomias prefrontais, pela técnica de Freeman e Watts. A topectomia consistiu sempre na ablação das áreas 9 e 10. Os resultados demonstram nítida superioridade da lobotomia, pois, enquanto esta técnica apresentava resultados excelentes em 15,15\% dos casos, nenhum paciente operado pela topectomia pôde ser considerado melhorado de modo excelente; $25,75 \%$ dos casos de lobotomia apresentaram bons resultados, contra $25 \%$ dos de topectomia; $15,15 \%$ dos operados pela Iobotomia apresentaram melhoras relativas, enquanto a topectomia melhorava 12,5\%; dos casos piorados, 44,12\% sofreram lobotomia e $56,25 \%$ a topectomia. Os AA. chamam a atenção para o fato de terem abandonado o emprêgo da topectomia em virtude dos resultados pouco favoráveis e em virtude da alta mortalidade (6,70\% contra $1,15 \%$ nos casos de lobotomia).

\section{J. Armbrustr-Figueiredo}

O tratamento da paralisia de Bell pela cortisona ('l'meatien't of Blel's palsy with cortisone). W. P. Robinson e B. F. Moss. J.A.M.A., 154:112-143 (janeiro) 1954.

Diversas hipóteses patogênicas (neurite infecciosa especifica, disfunção vascular com isquemia secundária do nervo facial, refrigeração, infecção mastóidea subclínica comprometendo a região do canal de Falópio, estenose congênita do canal facial associada a algum fator precipitante) foram aventadas para explicar a paralisia facial de Bell, embora nenhuma satisfaça completamente, de modo que a maioria dos casos recebe o rótulo de "idiopática".

Na presente nota clínica, os AA. registran dois casos seguidos de rápida recuperação após o uso de cortisona por via oral. Nítidas melhoras foram observadas após 3 dias de tratamento, no primeiro caso; no segundo, a cura clínica se verificou no $17^{\circ}$ dia. Os AA. reconhecem ser pequena sua casuística, mas acham justificável essa orientação terapêutica em outros casos precoces da afeç̧ão.

R. Melaragio Filho 
Primidona No tratamento da billepsla vão idopática (Primidone in the treatment of non-ibiopathic epllepsy). P. W. Nathax. Iancet, 266:21-22 (2 janeiro) 1954.

Neste trabalho, Nathan verificou os resultados obtidos em 21 pacientes com convulsões originadas de afecções cerebrais orgânicas, sendo 7 casos de hemiplegia infantil ou congênita, um de hemiplegia conseqüente a encefalite contraída com a idade de um ano, um de porencefalia, 4 de tumores intracranianos, um com traumatismo craniano, um após abscesso cerebral, 2 com atrofia cortical generalizada, um caso de cisto do lobo temporal e 5 pacientes com foco eletrencefalográfico de atividade contínua. Em todos êsses pacientes, o tratamento prévio, de vários anos, pelo fenobarbital e pela tenil-hidantoína sódica havia falhado. Não obstante, $43 \%$ dos pacientes demonstraram nítidas melhoras e alguns chegaram a ficar livres de acessos por vários meses.

R. Mei.aragno Filho

Primidona (Mrsolink) no thatamento do pequkio mai. clínico em crianças (Primidon iN The treatment of cinical petit-mal in chinhex). J. N. Briges e J. Tucker. I ancet, 266:19-21 (2 janeiro) 1954.

Diversas drogas têm sido propostas para o tratamento do pequeno mal e os melhores resultados parecem ocorrer com o uso da tridiona, a qual, no entanto, não è desprovida de efeitos tóxicos secundários. Recentemente foi sintetizada substância nova e relativamente simples, a Primidona. Em casos assinalados na literatura, a Primidona reduzia a frequiência dos acessos do tipo PM, mas em grau menor que os do tipo GM. No presente trabalho, os AA. procuraram estudar os efeitos da droga em 22 crianças portadoras do tipo PM da epilepsia. Em 7, os acessos foram bem controlados durante, no minimo, 10 meses; em outros 7 a freqüência das crises decresceu sensivelmente. A dosagem requerida é maior que nos adultos, variando de 0,125 a $1,500 \mathrm{~g}$ por dia. Os efeitos secundários, como ataxias e dôres abdominais, podem ser intensos nos primeiros dias, mas tendem a desaparecer com o prosseguir do tratamento. A Primidona pode ser eficiente mesmo nos casos em que falha a tridiona; eventualmente pode determinar nitidas melhoras clínicas sem modificar os traçados eletrencefalográficos.

\section{R. Mei.aragno Filmo}

Avaliação clínica da Mesantoln na epilepsia (a clinical evaidation of Megantoin in epilepsy). A. W. Malis e G. D. Gammon. J. Nerv. a. Ment. Dis., 118:193-203 (setembro) 1953.

Quarenta epilépticos crônicos foram submetidos a tratamento com Mesantoin, em substituição à difenil-hidantoína (Dilantin) que a maioria dêsses pacientes vinha usando, não sendo alterado o restante da medicação. Na maior parte dos casos, o tratamento até então usado não havia conseguido eliminar inteiramente as manifestações comiciais. Os AA. consideram que o grupo de pacientes escolhidos constituía um problema difícil do ponto de vista terapêutico, pois a frequiência das crises era de 6,6 por mês, por paciente, em média. Em sua maior parte, tratava-se de casos classificados como idiopáticos (27 casos). A terapêufica anteriormente usada pelos pacientes consistia em um ou vários dos medicamentos: difenil-hidantoína (Dilantin), feniletilmaloniluréia (Fenobarbital) e trimetiloxazolidinadiona (Tridione). Em 25 dos 40 casos haviam sido observadas reaçôes tóxicas com tal terapêutica: hipertrofia gengival, ataxia, vertigem, distúrbios 
da palavra, distúrbios da conduta, psicose, dermatite, prurido, sonolência, neutropenia, nistagmo, diplopia e outros distúrbios visuais. Quanto aos tipos de crises, foram classificados em pequeno mal, grande mal, jacksoniano e psicomotor. Os melhores resultados colhidos com a medicação ensaiada foram obtidos em pacientes que sofriam sòmente de crises tipo grande mal: de 10 casos, 8 ficaram livres das crises durante o periodo de observação (3 a 18 meses). O medicamento se revelou muito menos eficiente no tratamento das crises psicomotoras e jacksonianas; não foi estudado o efeito sôbre as crises tipo pequeno mal. Considerando em conjunto todos os tipos de crises, cêrca de $40 \%$ dos pacientes não as tiveram mais e. cêrca de $80 \%$ se beneficiaram com o tratamento (menor número de crises). A dose empregada variou de $0,05 \mathrm{~g}$ a $0,90 \mathrm{~g}$ por dia; a substituição do Dilantin por M'esantoin foi feita gradualmente, na maioria dos casos. Foram observadas reações tóxicas ao medicamento em 22 pacientes, sendo uma delas constituída por anemia aplástica, que acarretou a morte. As restantes complicações não ofereceram gravidade e desapareceram logo após a interrupção da medicação, não retornando quando ela foi instituída novamente. Em 18 pacientes não foram observadas quaisquer reações tóxicas; em 19, reações leves ("rash", sonolência, cefaléia, diplopia e outras); em 2, reações moderadas (respectivamente, psicose sam gravidade e delírio acompanhado do aumento do número de crises); o caso de morte referido é, segundo os AA., o quarto descrito na literatura. Em 2 casos em que o Dilantin havia provocado hipertrofia gengival, a substituição dêste medicamento por Mesantoin foi seguida do desaparecimento dessa complicação; em um caso de ataxia grave consequiente ao mesmo tratamento, melhora progressiva foi observada quando tal medicamento foi substituído por Mesantoin. Os AA. não procuraram comparar a eficiência das duas hidantoínas, consideradas em doses iguais; a Mesantoin foi empregada nas doses máximas toleradas. Concluem que 77\% dos pacientes se heneficiaram com a substituição de Dilantin por Mesantoin; $18 \%$ não experimentaram melhora, ou então, apenas ligeira diminuição no número de crises, e 5\% pioraram sob a influência do tratamento instituído. Em sua opinião, a Mesantoin é um composto de grande utilidade, que traz o inconveniente de poder causar neutropenia, o que não se descreveu ainda para o Dilantin, e que produz, com mais treqüência que êste, "rash" cutâneo; pode substituir o Dilantin nos casos de hipertrofia gengival e, possivelmente, nos de ataxia provocada pelo mesmo medicamento. As reações tóxicas, embora tendo ocorrido em cêrca de $50 \%$ dos casos, foram geralmente de caráter benigno e, muitas vêzes, desapareceram com a continuação do tratamento.

Adail Freitas iulião

Reabilitação nas neuropatias crônicas (Rehabilitation in chronic Neurologic Disease). V. R. Zarling. Neurology, 4:147-156 (fevereiro) 1954.

O A. apresenta a avaliação parcial dos resultados obtidos durante 4 anos e meio de atividades no Departamento de Neurologia do Minneapolis Veterans Hospital, com o emprêgo de um programa de reabilitação em pacientes com neuropatias crônicas. O programa inclui, na avaliação total do paciente, o exame clíniconeuro-psiquiátrico, social e vocacional, estabelecendo a orientação terapêuticia, com base nesta avaliação.

Concluindo, o A. estabelece que a reabilitação do paciente com neuropatia crônica requer um programa integrado por todos os departamentos; a reabilitação total processou-se em 466 pacientes num período médio de 12 semanas; o tipo de moléstia é o fator mais importante na avaliação da reabilitação total; a idade é o fator menos importante, com exceção daqueles com mais de 65 anos; o programa de reabilitação diminui o período de hospitalização, sendo benéfico do ponto de vista material e da estabilidade psíquica do paciente. 


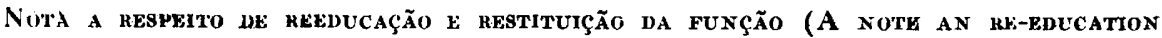
and restitution of function). D. G. Forgays. J. Nerv. a. Ment. Dis., 118 : 363-368 (outubro) 1953.

O A faz um breve estudo retrospectivo, crítico e comparativo, a respeito do retôrno da função em casos de lesões cerebrais. Enquanto, para alguns autores, upós a lesão cerebral haveria um processo de facilitação e a recuperação se faria espontáneamente, outros acreditam ser necessária uma reeducação da função perdida. O A. discute as hipóteses atuais do mecanismo da volta à função $e$ até que ponto haveria influência da reeducação. O $\mathrm{A}$. cita um caso em que houve perda da visăo, pós-lobotomia, no qual, um mês após, a recuperação era parcial, sendo que, instituída a reeducação, o paciente recuperou-se completamente. Conclui que a avaliação dos efeitos da reeducação deve aguardar estudos posteriores do problema, com um contrôle rigoroso das possibilidades da reeducação após as lesões orgânicas.

\section{A. Avghinam}

l'ziquisa sôpre o psicograma de Rorschach Nas cerebropatias orgânicas (RichehChe sullo psicograma alla Rorschach nelie cerebropatie organiche). V. Por'TA E U. Marzuor.t. Riv. di Neurol., 23:241-268 (maio-junho) 1953.

E' importante salientar que o presente trabalho, dedicado ao estudo do psicodiagnóstico de Rorschach nas psicoses orgânicas, é feito em colaboração por dois neurologistas. Aceitando os sinais já estabelecidos por Piotrowski no estudo de Rorschach, critica o método usado por êsse autor, que considerou, a priori, a afecção cerebral como unidade, sem qualquer preocupação com a localização do processo patológico. Citam Harrover Erickson, cujos estudos já proporcionam meios, não só de localização de tumores cerebrais, como de diferençar os tumores da hipertensåo intracraniana. Propõem estudar o psicograma em um número elevado de afeç̧ões orgânicas do cérebro, principalmente os tumores cerebrais, focalizando determinados quesitos, tais como: quais os sinais do Rorschach para o diagnóstíco da síndrome orgânica? que permite afirmar o diagnóstico diferencial nos casos duvidosos, por exemplo com a síndrome neurótica pós-traumática ou com a reação psicógena da encefalopatia? o psicograma das moléstias orgânicas do cérebro, além da verdadeira demência, apresenta elementos distintivos da norma? é possível a diferenciação das demais síndromes mentais? é possível diferençar com o Rorschach características em relação com a localização, a extensão, a etiologia, a sintomatologia e o decurso da lesão orgânica? no caso especial de tumores, é reconhecível a influência de fatôres acessórios, como a hipertensão intracraniana e a epilepsia sintomática? permite o método de Rorschach descobrir modificações orgânicas da personalidade que não aparecem ao exame psíquico? e, finalmente, fornece dados novos à interpretação psicopatológica?

Para éste programa tão extenso e importante, os $\Lambda \mathrm{A}$. estudaram 102 casos, assim especificados: 45 casos de tumores cerebrais, com suas respectivas localizações; 8 de hipertensão sem sintomas focais; 16 de lesões vasculares; 12 de lesões traumáticas; 12 de lesões diversas. Analisam cuidadosa e minuciosamente os protocolos colhidos e fazem extensas considerações e críticas dos resultados obtídos. Entre suas conclusões, se salientam: o método de Rorschach permite, em um bom número de casos, reconhecer, ou pelo menos suspeitar, a presença de uma lesão orgânica do cérebro, embora em contraste com a primeira impressão clínica. Confirmam os AA. a psicossindrome orgânica no Rorschach, já delineada pelos pesquisadores anteriores, excluindo que essa possa limitar-se aos 10 pontos da série de Piotrowski. Como sinais novos, assinalan: a instabilidade do comportamento churante a prova, a lassidez associativa, a descoordenação (Spaltung), a cinesia de imitaçăo; descrevem algumas características especiais para as lesões frontais, a hipertensão primitivn, lesões vasculares e outras. 


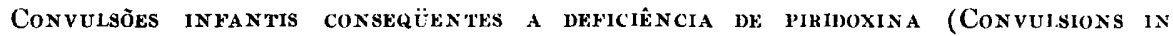
yodNG infants as a result of pyridoxine [Vitamin $B_{6}$ ] deficiency). C. J. Molony e A. H. Parmelee. J.A.M.A., 154:405, 1954.

Os AA. referem que, durante o ano de 1952 e princípios de 1953, em tôdas as regiões dos E.U.A.N. surgiram casos de crianças na primeira infância apresentando convulsões epileptiformes, não associadas a qualquer sinal de moléstia orgânica ou qualquer fator etiológico sugestivo. Tratava-se de crianças com história normal de nascimento e desenvolvimento até 16 semanas de idade, quando sùbitamente ocorriam convulsões generalizadas, muitas vêzes várias por dia. Os FEG mostraram leves anormalidades não localizadas. Observaram, entretanto, que tôdas essas crianças recebiam alimentação artificial, por um produto do Laboratório Wyeth, constituído principalmente de leite de vaca desnatado, gorduras vegetais e animais, vitaminas e ferro. Tôdas as crianças, depois de alimentadas com outra fórmula de leite ou recebendo alimentos suplementares como cereais, frutas, carnes e vegetais, ficaram livres das convulsões. Os AA. apresentam 6 casos bem demonstrativos da relação causal entre o alimento e a ocorrência das convulsões. Em estudos de colaboração com o Laboratório Wyeth chegaram à conclusão de que o fator etiológico convulsiógeno era a deficiência de piridoxina (vitamina $B_{6}$ ).

Os AA. ressaltam a importância da vitamina $B_{6}$, relatando trabalhos de Chick, em 1940, que foi o primeiro a registrar a ocorrência de convulsões em ratos e porcos alimentados com dietas sem piridoxina. Synderman, em 1950, fêz o primeiro registro de convulsões em seres humanos por deficiência de piridoxina. No J.A.M.A., de 22-9-1951, o assunto foi exposto detalhadamente. Os AA. salientam os perigos existentes nas tentativas de copiar industrialmente o leite humano, que tem alto teor de piridoxina.

Julgamos de grande importância o conhecimento desta eventualidade, principalmente entre nós, onde a alimentação artificial de crianças se está tornando quase habitnal e também no sentido de não desprezarmos o uso da vitamina $B_{6}$ como auxiliar no tratamento anticonvulsivante.

JoY ARRt'd

Convulsões INFANTis COM DIETAS DEFICIENTES EM PIRIDOXINA (Convulsive SEIzURes in infaNts With pyridoxine-deficient diet). D. B. Counsin. J.A.M.A., 154:406$408,1954$.

O A. faz uma revisão do estudo da síndrome de hiperirritabilidade e ataques convulsivos ocorrida em crianças em 1951-1953, cujo fator etiológico ficou evidenciado ser a deficiência de vitamina $B_{6}$ em virtude da alimentação artificial com o produto SMA, do Laboratório Wyeth. Reuniu um grupo de 54 observações dêstes pacientes, que claramente demonstram a necessidade de piridoxina na nutrição. Descreve minuciosamente um caso e tece comentários a respeito do assunto e dos trabalhos já existentes; dentre êstes, cita Ernsting e Ferwerda, que registraram alguns resultados favoráveis do uso de piridoxina no tratamento da epilepsia. 